\title{
Temporary seismic monitoring of the Sulmona area (Abruzzo, Italy): a quality study of microearthquake locations
}

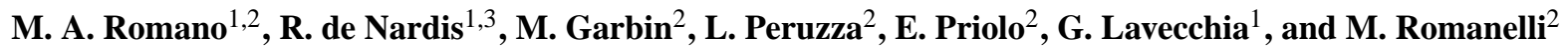 \\ ${ }^{1}$ GeosisLab, DiSPUTer, Università G. d'Annunzio, Campus Universitario di Madonna delle Piane - \\ 66013 Chieti Scalo (CH), Italy \\ ${ }^{2}$ Centro Ricerche Sismologiche, Istituto Nazionale di Oceanografia e Geofisica Sperimentale, Via Treviso, 55 - 33100 Udine, \\ Italy and Borgo Grotta Gigante, 42/C - 34010 Sgonico (TS), Italy \\ ${ }^{3}$ Dipartimento della Protezione Civile, Via Vitorchiano, 2 - 00189 Rome, Italy
}

Correspondence to: M. A. Romano (aromano@inogs.it)

Received: 22 April 2013 - Published in Nat. Hazards Earth Syst. Sci. Discuss.: 29 May 2013

Revised: 18 September 2013 - Accepted: 29 September 2013 - Published: 5 November 2013

\begin{abstract}
Thanks to the installation of a temporary seismic network, a microseismicity study has been conducted in the Sulmona area (Abruzzo, Italy) with the aim of increasing the knowledge of seismogenic potential of existing active faults. In this work the first 7 months (from 27 May to 31 December 2009) of recorded data have been analysed over a total period of acquisition of about 30 months. Using a semi-automatic procedure, more than 800 local earthquakes have been detected, which highlights the previously unknown background seismicity. About $70 \%$ of these events have been relocated using a 1-D velocity model estimated specifically for the Sulmona area. The integration of temporary network data with all the other data available in the region enables us to obtain a statistically more robust data set of earthquake locations. Both the final hypocentral solutions and phase pickings are released as a supplement; an appendix also describes phase readings' quality with respect to weighting schemes used by location algorithms. Local magnitude values of the newly detected events range between -1.5 and 3.7 and the completeness magnitude for the Sulmona area during the study period is about 1.1. Duration magnitude coefficients have been estimated as well for comparison/integration purposes. The local Gutenberg-Richter relationship, estimated from the microseismic data, features a low $b$ value, tentatively suggesting that the Sulmona area may be currently undergoing highstress conditions, in agreement with other recent studies. The time-space distribution of the seismic activity with respect to the known active faults as well the seismogenic layer thickness are preliminarily investigated.
\end{abstract}

\section{Introduction}

A small, temporary seismometric network was deployed in the Sulmona area (central Italy, Fig. 1) during the seismic sequence which followed the devastating L'Aquila 2009 earthquake (6 April, $M_{\mathrm{w}}=6.3$; Chiaraluce et al., 2011; Lavecchia et al., 2012) with the aim of increasing the knowledge of the seismogenic potential of existing active faults. This network began operation on 27 May 2009 and continued till its end in 22 November 2011.

In the study area, some active faults are deemed capable of generating impending strong earthquakes by seismotectonic and seismic hazard studies (e.g. Boncio et al., 2004; Pace et al., 2006; Peruzza et al., 2011; De Natale et al., 2011). Nevertheless, during the last decades, the area has been almost completely aseismic, with only very minor and sporadic events (in a $20 \mathrm{~km}$ distance from Sulmona, $M=3.7$ in October 1992, from the CSI database (Castello et al., 2006), and $M=3.8$ in March 2009, from the ISIDE database (ISIDE Working Group, 2010)). Low seismicity rates have also been found by the experiment performed through a temporary seismic network by Bagh et al. (2007). So the main goal of our temporary seismic survey was to highlight the occurrence of microseismicity not located by the Centralized National Seismic Network (RSNC) and the Abruzzo Seismic Network (RSA) during the post-seismic phase of the 2009 earthquake, and to recognize, if any, the space-time evolution of brittle deformations on the major faults of the area. 

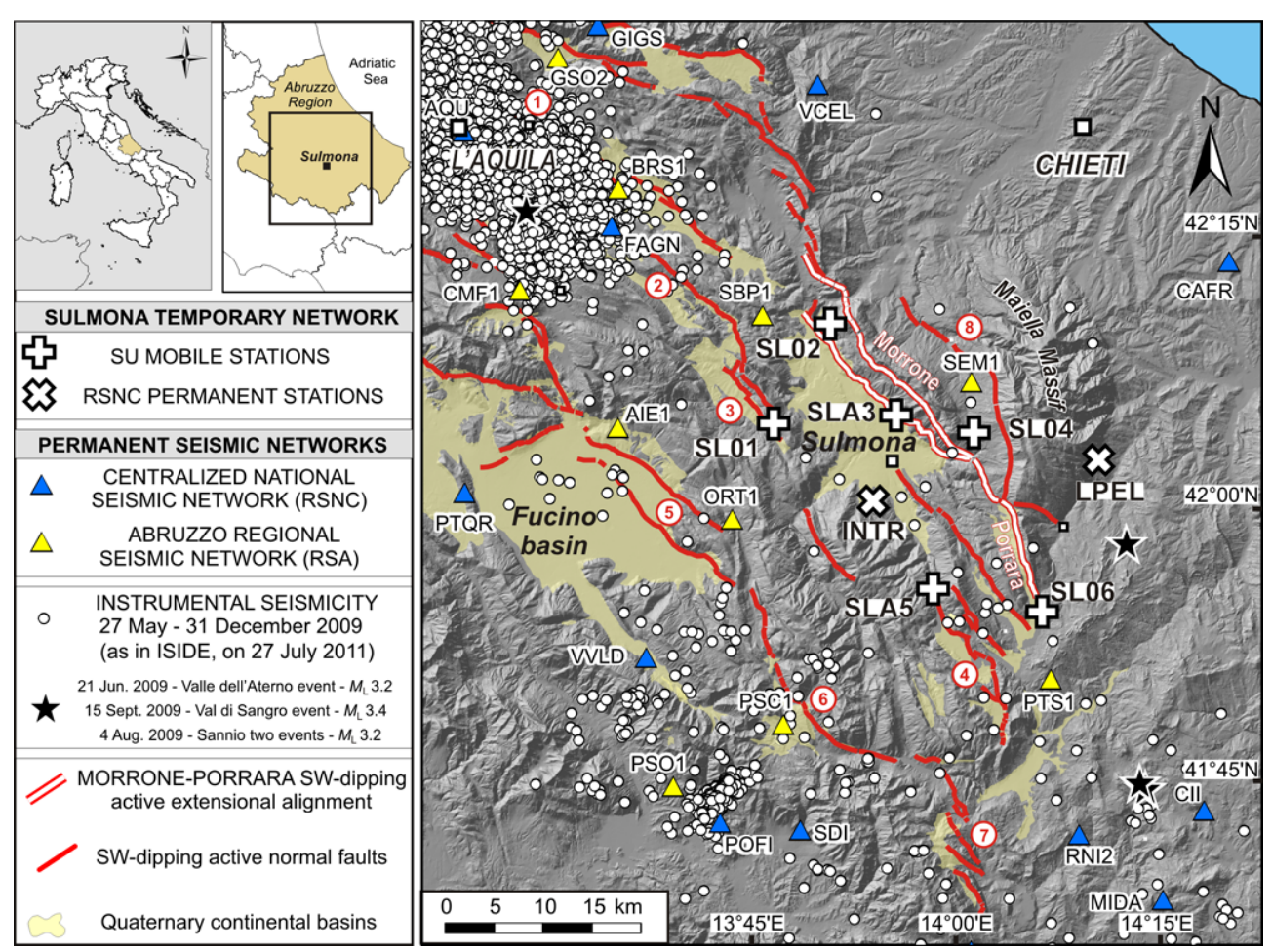

Fig. 1. Station locations and epicentral distribution of seismic events recorded by the INGV National Seismic Network (RSNC, http://iside. rm.ingv.it/iside/standard/index.jsp) in the Sulmona area (Abruzzo region) during the period 27 May-31 December 2009. The black stars indicate the epicentres of the strongest events located in this study; these are listed in the legend, from north to south. SU stations are labelled by pluses; crosses show the two permanent stations of the RSNC acquired in continuous recording mode and treated offline as data exchange. Selected permanent stations of the RNSC and of the Abruzzo Regional Seismic Network (RSA; see De Luca, 2011) were used in this study and are marked by blue and yellow triangles, respectively. The red numbers correspond to fault systems cited in the text.

Reliability and accuracy in earthquake location are topics often neglected by earthquake catalogues; they are even less properly addressed when data sets come from temporary monitoring and earthquake distribution is used to support geological and structural interpretations. As discussed by Lee and Stewart (1981), locating local events accurately requires considerable efforts: good station coordinates, reasonable crustal structure models and reliable $P$ and $S$ readings are necessary but not sufficient conditions, as earthquake location is a non-linear problem, and no "fool-proof" method exists if input data are not sufficient to constrain the problem (Husen and Hardebeck, 2010).

In this study, we analyse the first seven months of our seismic recordings (e.g. from 27 May to 31 December 2009). Data were acquired in continuous recording mode and processed offline by an offline semi-automatic procedure. In addition, they required ad hoc manual elaborations, as small local earthquakes were blurred in the ongoing intense activity of the L'Aquila seismic sequence, and the noise level at temporary sites was high in some cases. Details on the detection/recognition procedures and data preprocessing are given in de Nardis et al. (2011). By integrating the data recorded by our temporary network with those retrieved from national and regional permanent networks (globally, 76 stations spread over an area of about $54000 \mathrm{~km}^{2}$ ), a final data set of nearly 7000 phase readings and of about 800 located earthquakes was obtained.

This paper has two main goals: (1) to quantify the precision of phase readings and the accuracy of the locations, by exploring crustal velocity models and location algorithms, in order to release an original data set of small magnitude earthquakes for the Sulmona area (provided as a supplement); and (2) to estimate the completeness magnitude threshold and a reliable Gutenberg-Richter characterization of background seismicity of the study area, useful for seismic hazard purposes. Preliminary considerations on the seismogenic layer thickness and on the geometric links with the active faults pattern, based on the space-time distribution of microseismicity, are also advanced.

After presenting the temporary network in the tectonic framework of the Sulmona Basin and surrounding areas (Sect. 2), we show how we built our arrival times data set and assessed its reliability in terms of uncertainty (Sect. 3). Then we describe the procedure adopted for computing the local velocity model (Sect. 4), which is afterwards used in locating the recorded microseismicity (Sect. 5). Next, we focus on 
magnitude estimates, together with the completeness threshold and Gutenberg-Richter parameters (Sect. 6). Finally, we discuss our results (Sect. 7).

\section{The Sulmona temporary seismic survey in the seismotectonic context}

On 27 May 2009 OGS (Istituto Nazionale di Oceanografia e di Geofisica Sperimentale) and GeosisLab (Laboratorio di Geodinamica e Sismogenesi, Chieti-Pescara University) installed a temporary seismometric network around the Sulmona Basin (Fig. 1). This sector of the central Apennines is adjacent to the area extensively covered by temporary stations after the $M_{\mathrm{w}}=6.3 \mathrm{~L}$ 'Aquila earthquake (see, for example, Margheriti et al., 2011).

The Sulmona Plain is one of the intermountain basins of the Abruzzo Apennines, east of the best-known Fucino Basin (Fig. 1). It is filled by lacustrine continental deposits of Pleistocene-Holocene age and it is bounded eastward by the Morrone normal fault system. This system is characterized by two SW-dipping sub-parallel segments extending for nearly $20 \mathrm{~km}$ along strike (Gori et al., 2011); the westernmost one shows a huge fault scarp at the contact between the carbonate bedrocks and slope deposits. It dislocates late Pleistocene (related to the Last Glacial Maximum) alluvial fan and slope deposits, and therefore is considered active (Gori et al., 2011). Southeastward of this, the Morrone fault system continues in the SSW-dipping Porrara normal fault, which runs about $18 \mathrm{~km}$ in the NNW-SSE direction.

Other active extensional structures outcrop on the outskirts of the temporary network (Boncio et al., 2004; Galli et al., 2008; Lavecchia et al., 2012). They are the Paganica, the Middle Aterno Valley and the Conca Subaequana faults (no. 1, 2 and 3, respectively in Fig. 1), the Cinque Miglia Fault (no. 4 in Fig. 1), the Fucino Fault (no. 5 in Fig. 1) and its southward continuation into the Marsicano and Barrea faults (no. 6 and 7 in Fig. 1, respectively). Eastward of the Morrone-Porrara system, an impressive SW-dipping normal fault outcrops, known as the "Caramanico Valley fault" (no. 8 in Fig. 1). The Quaternary activity of such a structure, which bounds the Maiella Massif to the west, is still controversial in the literature (Ghisetti and Vezzani, 2002; Galadini and Messina, 2004; Elter et al., 2012).

Since early times in instrumental seismometry, there have been only a few recorded activations in the region: the Fucino Fault was activated by the 1915 Avezzano earthquake $\left(M_{\mathrm{w}}=7\right)$, the Paganica Fault by the 2009 L'Aquila earthquake $\left(M_{\mathrm{w}}=6.3\right)$ and the Barrea Fault by the 1984 Val di Sangro earthquake $\left(M_{\mathrm{w}}=5.4\right)$. No relevant instrumental earthquake is associated with the Morrone-Porrara alignment, which up to now has been only characterized by very minor instrumental activity (Castello et al., 2006; ISIDE Working Group, 2010; Bagh et al., 2007). Conversely, in historical times, the Sulmona Plain was the site of three destructive earthquakes, which occurred in the second century $\mathrm{AD}\left(M_{\mathrm{w}}=6.6\right.$; Ceccaroni et al., 2009), in November $1706\left(I_{\max }=\mathrm{X} / \mathrm{XI}\right.$ MCS $\left.M_{\mathrm{w}}=6.8\right)$ and in September $1933\left(I_{\max }=\right.$ IX MCS, $\left.M_{\mathrm{w}}=5.97\right)$ (Rovida et al., 2011; Guidoboni et al., 2007).

The OGS-GeosisLab temporary network, hereinafter referred to as STN (Sulmona temporary network), consists of six mobile stations (SU network code in OASIS (Working Group OASIS, 2011), the OGS Archive System of Instrumental Seismology, in the section "Sites"). These stations are integrated by two permanent ones (INTR and LPEL, IV network code in iside.rm.ingv.it/iside/standard/result.jsp? rst=1\&page=STATIONS, last access: 22 February 2012) belonging to the RSNC, which is managed by the INGV (Istituto Nazionale di Geofisica e Vulcanologia), for which continuous recordings were given as data exchange (see Table 1). The stations were located on both the hanging wall and the footwall of the Mt Morrone and Mt Porrara faults, with an inter-station distance of about $10 \mathrm{~km}$ (Fig. 1). Acquisition was set in continuous recording mode, and the collected data were managed at the OGS by the Antelope system (BRTT, 2004). The network had been operating for 30 months when the removal of all the mobile stations occurred on 22 November 2011. Some STN stations were moved during the monitoring for logistical reasons as well as in order to improve their performance. A full description of the sites, the equipment and their functioning period is available at the OASIS website.

\section{Waveform data processing and data set of arrival times}

The STN seismological survey provided a huge amount of continuous seismic recording data $\left(190 \mathrm{MB} \mathrm{day}^{-1}\right)$. However, the advantage of having a complete data set runs into the drawback of needing an effective strategy in order to distinguish weak seismic signals from noise. Here we analyse only the data acquired during the first seven months as they required peculiar data treatment due to the ongoing L'Aquila sequence, including manual operations hereinafter described. In this section we also refer to a preliminary location, which represents an essential step of our work. Indeed it allowed for the integration of our data with those from other existing networks, thanks to the origin times, and the selection of good-quality events through which we refine the velocity model.

\subsection{Earthquake detection and preliminary location}

The first step of this study is to recognize all the local seismicity, down to the weakest events, from the STN waveform data. In the period analysed in this experiment, the microseismicity detection was hampered by the ongoing L'Aquila seismic sequence, which started some months before the 
Table 1. Main characteristics of the Sulmona Temporary Network: data taken from the OGS and INGV sites' archives. SLA is the identification code of relocated SLO stations.

\begin{tabular}{|c|c|c|c|c|c|c|}
\hline $\begin{array}{l}\text { Station Code/ } \\
\text { Network }\end{array}$ & $\begin{array}{l}\text { Municipality } \\
\text { (PROVINCE) }\end{array}$ & $\begin{array}{l}\text { Lon } \\
\text { (DD) }\end{array}$ & $\begin{array}{l}\text { Lat } \\
\text { (DD) }\end{array}$ & $\begin{array}{l}\text { Elevation } \\
\text { (m a.s.1.) }\end{array}$ & $\begin{array}{l}\text { Date } \\
\text { ON/OFF }\end{array}$ & $\begin{array}{l}\text { Sensor/ } \\
\text { Data Logger }\end{array}$ \\
\hline SL02/ & Popoli & 13.8539 & 42.1745 & 684 & $27-05-09 /$ & CMG-40, FBA ES-T/ \\
\hline SU & (PESCARA) & & & & $22-11-11$ & RefTek RT 130 \\
\hline SU & (L'AQUILA) & & & & 01-10-09 & RefTek RT 130 \\
\hline SLA3/ & Sulmona & 13.9342 & 42.0895 & 523 & 01-10-09/ & Lennartz-3Dlite/ \\
\hline SU & (L'AQUILA) & & & & $22-11-11$ & RefTek RT 130 \\
\hline SL04/ & Pacentro & 14.0296 & 42.0730 & 1281 & $26-05-09 /$ & Lennartz-3Dlite/ \\
\hline SU & (L'AQUILA) & & & & $22-11-11$ & RefTek RT 130 \\
\hline SL05/ & Rocca Pia & 13.9787 & 41.9371 & 1067 & $26-05-09 /$ & Lennartz-3Dlite/ \\
\hline SU & (CHIETI) & & & & $24-03-10$ & RefTek RT 130 \\
\hline INTR/ & Introdacqua & 13.9046 & 42.0115 & 924 & 09-03-03/ & Trillium 40S/ \\
\hline IV & (L'AQUILA) & & & & - & Trident-FS-16-VPP SG-1 \\
\hline LPEL/ & Lama dei Peligni & 14.1832 & 42.0468 & 760 & 11-04-08/ & Trillium 40S/ \\
\hline IV & (CHIETI) & & & & - & GAIA2-FS-16-VPP \\
\hline
\end{tabular}

STN deployment and culminated in the deadly events of 6 April 2009 at 03:32 LT $\left(M_{\mathrm{w}}=6.3\right.$; Chiaraluce et al., 2011) and by the high level noise of some stations due to the temporary installation of sensors. Therefore, in order to gain the maximum sensitivity, a semi-automatic procedure has been applied, similar to that used by Garbin and Priolo (2013) for detecting small magnitude events in the Trento province, which combines automatic detection of all possible events and true event identification with visual inspection. This procedure is part of the general system implemented at CRS (Centro di Ricerche Sismologiche) for processing seismological data. It uses (1) Antelope (BRTT, 2004) for acquiring/storing data, recognizing earthquakes automatically, and extracting earthquake waveforms; and (2) a "pick server" for phase picking and location, which are performed by Seisgram2K (Lomax, 2008) and Hypo71 (Lee and Lahr, 1975), respectively.

Earthquake recognition is performed by a sequence of two operations, i.e. trigger detection and trigger association, performed by Antelope through dbdetect and dbgrassoc functions, respectively. The first one uses a classical short-time average/long-time average (STA/LTA), while the second one declares an event when a group of detections is found to be compatible with the theoretical travel times for a unique source. There are several parameters controlling these algorithms (e.g. pass-band filtering), and the selection of their best combination is not trivial. False events (very frequent in noisy sites) increase with the choice of decreasing the
STA/LTA threshold and using a low number of minimum stations, aimed at increasing the overall sensitivity of the automatic recognition. They can be identified and removed by human visual inspection.

Applied to the whole 7-month data set, the automatic procedure extracted about 16000 windows of signal, which included teleseismic events, regional events (for example the L'Aquila aftershocks), local earthquakes (our target) and false events. All the windows were visually inspected, but only those containing local events (with time difference between $P$ and $S$ arrivals of less than about $3 \mathrm{~s}$ ) were analysed. About 4700 phases were recognized and manually re-picked, identifying more than 800 microearthquakes. About $70 \%$ of these events with more than three phases were preliminarily localized by using the Hypo71 code (Lee and Lahr, 1975) and the velocity model used for ISIDE locations (Fig. 2).

The detection capabilities of the STN network obviously decrease by increasing the event-to-station distance. In fact, in a buffer zone corresponding to a $20 \mathrm{~km}$ distance from each STN station, the RSNC events (http://iside.rm.ingv.it/ iside/standard/index.jsp, last access: 22 February 2012) are $35 \%$ of the ones localized by STN network (104 earthquakes versus 293), while they rise to $73 \%$ (264 by RSNC versus 359 by STN) if the distance is set to $25 \mathrm{~km}$. Several singlestation events were detected as well (e.g. in Fig. 3), but they may be located in terms of $S-P$ distance only; most of them were recorded by SL06 station, at the southern tip of the Mt Porrara Fault. In conclusion, as a result of the semi-automatic 


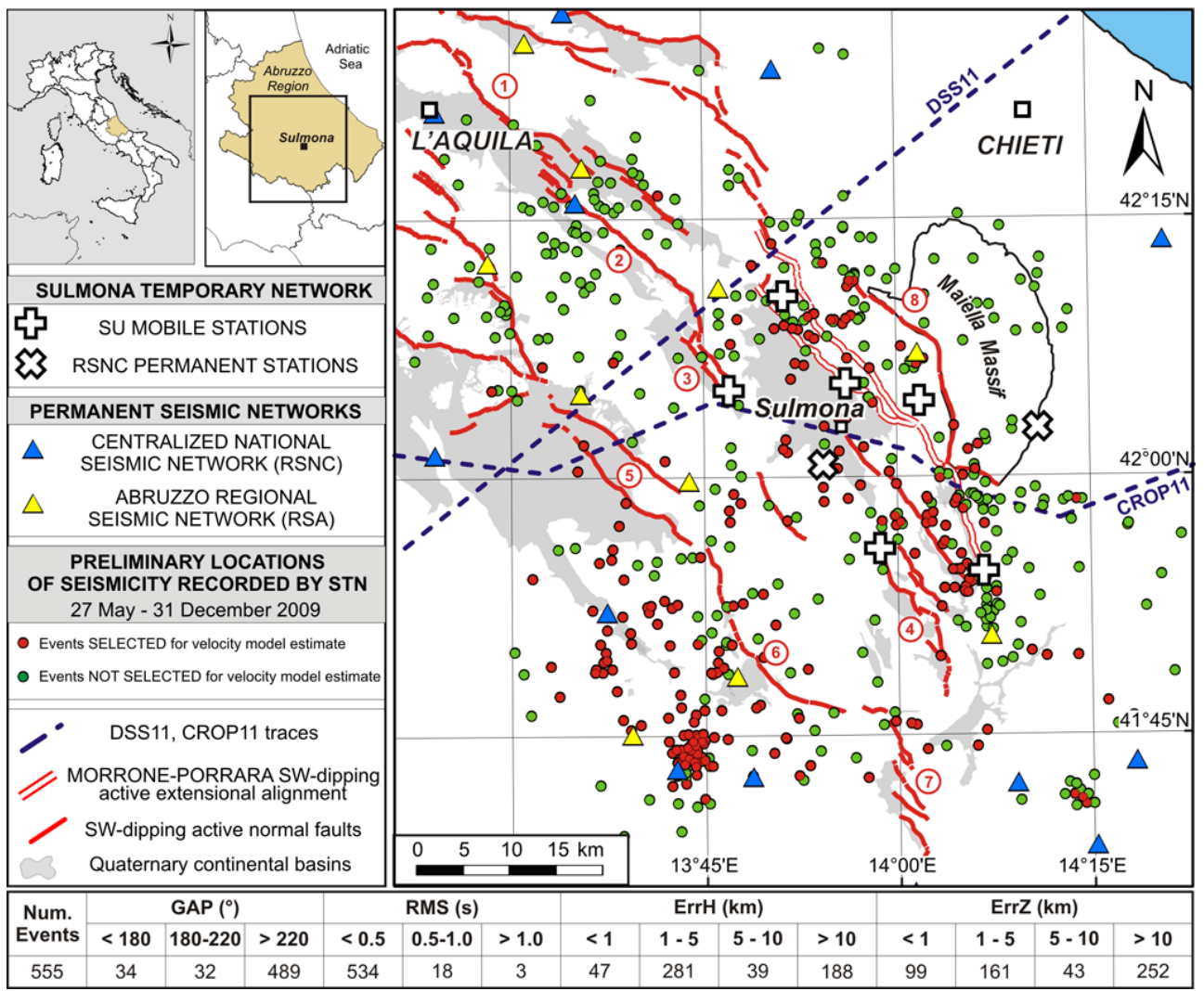

Fig. 2. Preliminary locations of earthquakes from 27 May to 31 December 2009 obtained with Hypo71 (Lee and Lahr, 1975) and the ISIDE velocity model. At the bottom is a summary of locations' quality (GAP, RMS, horizontal error (ErrH) and vertical error (ErrZ)).

event recognition and of a more dense temporary network, this study provides a much detailed data set for the Sulmona area than any other currently available for the Abruzzo. Bagh et al. (2007) detected in 18 months approximately the same number of events we did in 7 months but referred to a wider area.

\subsection{Improvement of phase readings}

The parameters commonly used to evaluate the quality of the earthquake locations (GAP, RMS, etc.; see Fig. 2) indicate that the quality of our preliminary data set is not enough for the purpose of seismotectonic analysis. With the aim of strengthening the earthquake catalogue, we integrated selectively the data, using other networks' data, and assessed the quality of phase readings and their overall reliability.

In particular, we included the data of the nearest six stations of the Abruzzo regional network (RSA, yellow triangles in Fig. 1) and of several stations of the national network (RSNC, blue triangles in the same figure) not acquired in real time during our experiment.

The RSA recordings are discontinuous, as stations work on triggers (De Luca, 2011). Time coincidences between the origin time of our local earthquakes and the automatic start time of RSA recordings have been examined. In 7 months,
37 triggered events correspond to earthquakes recognized by our network; $P$ and $S$ phases (black sector in Fig. 4a) were manually picked.

Similarly, the integration of our data set with other RSNC stations (INTR and LPEL are already part of the network experiment) has been accomplished by verifying time correspondence. Revised $P$ and $S$ arrival times from Italian Seismic Bulletin (http://bollettinosismico.rm.ingv.it/; last access: 22 February 2012) were merged with ours with no further revision on phase picks but avoiding the insertion of phases marked with a weight code greater than 4 . About $32 \%$ of the arrival times (yellow sector in Fig. 4a) now come from 60 RSNC stations (Fig. 1, blue triangles) collected.

The complete data set contains 6889 phases. It refers to 817 earthquakes, of which 382 were identified by 1 or 2 STN stations, and located only if having at least 4 phase readings; 225 were located exclusively by STN stations; and 210 were located through observations of STN, RSA and RSNC stations (Fig. 4a and b). Additional considerations on the quality of readings, the weighting scheme and their influence in the inversion procedure are given in the Appendix A.

Phase readings may be affected by systematic or random errors; however most of them can be identified and fixed through use of conventional analyses. We checked the 
28 MAY (148) 2009 - 20:52:11.000 - SL06
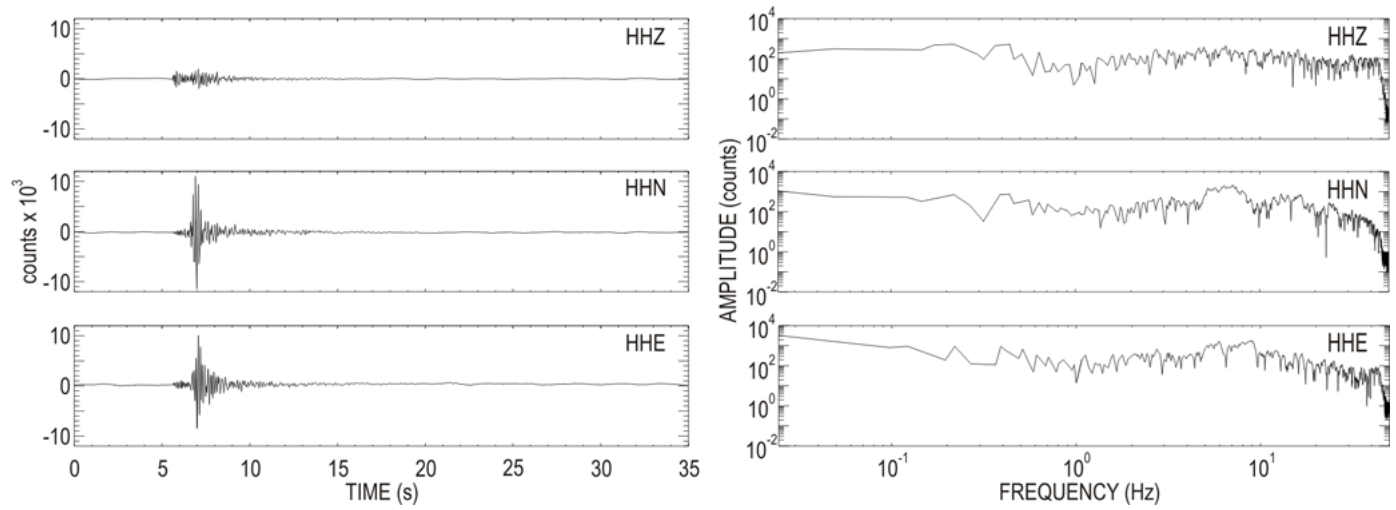

Fig. 3. Seismograms and amplitude spectra of a typical single-station event recorded by the three-component station SL06. Date and time above refer to starting point of the seismic trace. For this event, a source-station distance of about $8 \mathrm{~km}$ can be estimated from an $S-P$ time of $1 \mathrm{~s}$.
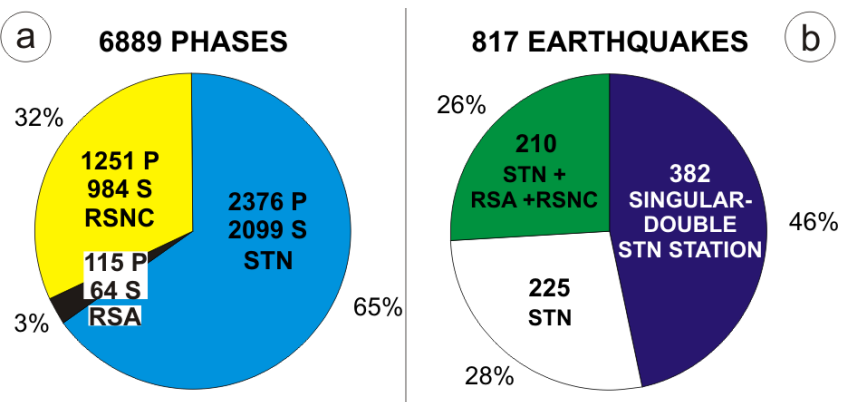

Fig. 4. Meta data obtained by the STN network in the first seven months. (a) Total number of seismic phases obtained after the integration of STN data with those from regional (RSA) and national (RSNC) permanent networks. (b) Total number of earthquakes representing our complete data set.

reliability and consistency of $P$ and $S$ phases by using the modified Wadati method (Chatelain, 1978), which compares the time difference of $P$ and $S$ phases recorded by pairs of corresponding stations. If we let $x_{i}$ and $x_{j}$ be the hypocentral distances of the $k$ event at two stations $(i, j)$, then the following equations hold:

$$
\begin{aligned}
\mathrm{DT}_{P} & =P_{i}-P_{j}=\left(x_{i}-x_{j}\right) / V_{P}, \\
\mathrm{DT}_{S} & =S_{i}-S_{j}=\left(x_{i}-x_{j}\right) / V_{S}, \\
\frac{\mathrm{DT}_{S}}{\mathrm{DT}_{P}} & =\frac{V_{P}}{V_{S}},
\end{aligned}
$$

where $P_{i}, P_{j}, S_{i}$ and $S_{j}$ are the $P$ and $S$ arrival times to stations $i$ and $j$, and $V_{P}$ and $V_{S}$ are the $P$ - and $S$-wave velocity values, respectively. Figure 5 a plots $\mathrm{DT}_{S}$ versus $\mathrm{DT}_{P}$ calculated for the original data and for all available pairs of STN stations for a total of 4716 phases. At this step, outliers are identified and removed, either by correcting or erasing the reading. Fig. $5 b$ is thus obtained, and it takes into account 241 picks removed from the original data set. Then, STN phase picks are integrated with those read from RSA stations or provided by RSNC stations for a total of 2414 additional phases. By refining and integrating the data set of phases, the $V_{P} / V_{S}$ estimated by ordinary least-squares regression (equation coefficients and line, with standard deviation, in red in Fig. 5) changes from 1.78 to 1.82 . The orthogonal regression (in blue in Fig. 5) results in more stable values - all around 1.85. Since orthogonal regression is more adequate for data affected by errors on both the variables, we choose as the final value the ratio $V_{P} / V_{S}$ equal to 1.85 , which is slightly higher than those obtained by other studies in the same region (1.83 by Bagh et al., 2007; 1.80 by De Luca et al., 2000; 1.77 by Boncio et al., 2009) but in agreement with the values estimated by Chiarabba et al. (2010) by local earthquake tomography, for which $V_{P} / V_{S}$ exceeds 1.83 .

\section{Estimate of local velocity model}

The systematic errors associated with the velocity model cannot be properly quantified, since earthquake hypocentres, earthquake origin times and seismic velocity structure (never exactly known) are intrinsically coupled (Husen and Hardebeck, 2010). Nevertheless, it is possible to estimate an optimized local velocity model which ensures the best tradeoffs between earthquake locations and the crustal model in terms of travel-time residuals. No specific velocity model to be used for event location is available for the Sulmona Basin and surrounding areas. As the number of earthquakes of this study is too small for feeding a 3-D tomographic inversion, we adopt a 1-D velocity structure inversion approach using the well-known Velest code by Kissling et al. (1994).

\subsection{Starting velocity models and selected data set}

In non-linear inversions which linearize the problem, it is crucial to define the initial guess accurately, since it affects 

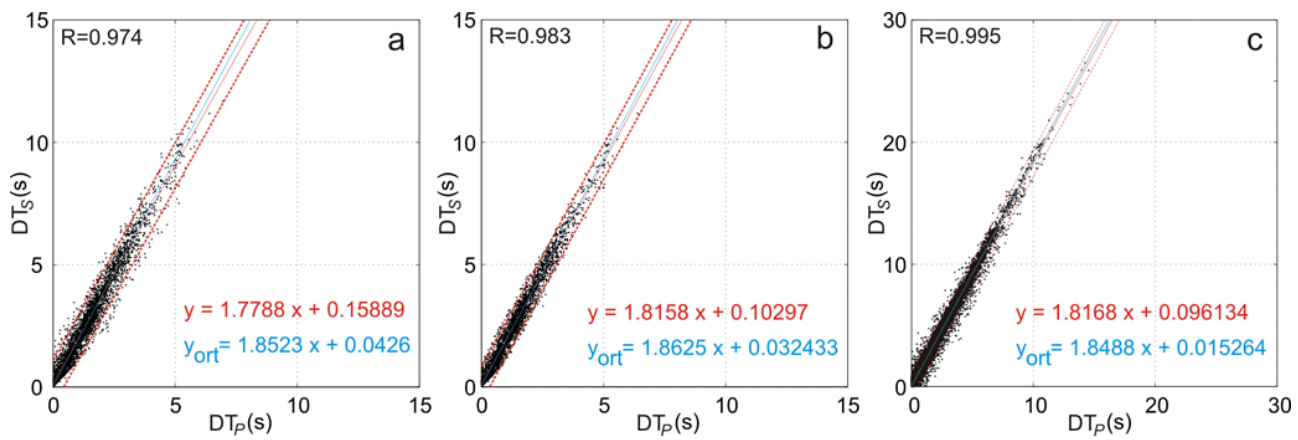

Fig. 5. Modified Wadati plot (Chatelain, 1978) of the arrival time data set of this study. (a) Initial data set of STN stations only. Red and blue lines represent ordinary least-squares (with its standard deviation) and orthogonal regression, respectively. Coefficients are given in the formula. (b) The same as (a) but after reading refinement and outlier removal. (c) Final diagram obtained after integration of other stations phase readings (either re-picked or as given by bulletins). Note the increase of linear correlation coefficient $R$ from (a) to (c), as well as the changes of $V_{P} / V_{S}$ for the two different regressions. The ratio $V_{P} / V_{S} 1.85$ is the final value chosen.

strongly the final solution. Therefore, we compiled a collection of possible velocity models across the study area, taking into consideration and integrating the available seismological, geophysical and geological information on the crustal stratigraphy in terms of layers thickness and seismic wave velocity. As a result, 121 -D $P$-wave velocity models with different structures were obtained and taken as a starting point to calculate a reliable velocity model (Fig. 6 and references therein).

Five models (a-e in Fig. 6) were derived from seismological data. Models (a), (b) and (c) are local velocity models optimized for the intra-Apennine area. They were obtained by inverting $P$ - and $S$-wave arrival times of local earthquakes recorded during a specific campaign (Bagh et al., 2007) or during the L'Aquila 2009 seismic sequence (northwestern sector of Fig. 1) (Chiarabba et al., 2009, 2010). Model (d) is a regional velocity model valid for the whole Italian territory and used for the Italian Seismic Catalogue CSI (1981-2001) (Chiarabba et al., 2005), and model (e) was derived from it, as explained in the next section. Three models (f-h) were the result of geophysical investigations such as deep seismic sounding data (DSS 11 by Scarascia et al., 1994; see the trace in Fig. 2) and near-vertical seismic reflection profiles (CROP 11 by Patacca et al., 2008; see Fig. 2), and were also opportunely integrated with results obtained from teleseismic receiver functions (Di Luzio et al., 2009). Models (i-1) were built by integrating and correlating the stratigraphic layering as derived from the interpretation of the geological structure at depth along a crustal section across the Sulmona-Maiella area (Lavecchia and de Nardis, 2009). Note that different $P$ wave velocity values have been attributed to the same layer by different authors (Patacca et al., 2008; Di Luzio et al., 2009; Barchi et al., 2003; Trippetta et al., 2013), and that the models often feature velocity inversions with depth (Fig. 6). Figure 7a emphasizes their great variability.

With the purpose of estimating the optimum 1-D velocity model, we selected the best-constrained earthquakes based on the quality of their preliminary locations and the recording stations represented in Fig. 7d. Since the study area is mainly characterized by sparse seismicity (except two relatively significant seismic sequences localized to the NW and SW of the Sulmona Basin, Fig. 2), we adopted two selection criteria. A more restrictive criterion was applied for the events located at the edge of the study area ( 107 events with RMS $\leq 0.5 \mathrm{~s}$, $\mathrm{GAP} \leq 180^{\circ}, \mathrm{N} \geq 10$ phase readings with at least 4 clear $S$ arrivals), and a less restrictive one for weaker earthquakes located within the local STN network (124 events with RMS $\leq 0.5 \mathrm{~s}, \mathrm{GAP} \leq 250^{\circ}, \mathrm{N} \geq 6$ phase readings with at least 2 clear $S$ arrivals). As a result, a subset of 231 events (red dots in Fig. 2) was obtained, with $P$ - and $S$-wave pickings having a mean reading uncertainty of 0.07 and $0.09 \mathrm{~s}$, respectively.

\subsection{Minimum 1-D velocity model from travel-time inversion}

Velest code (Kissling et al., 1994) allows for users to identify an optimum 1-D $P$ velocity model performing a simultaneous inversion of hypocentre locations, station corrections and the parameters of the velocity structure. As the global misfit (i.e. root mean square of all travel-time residuals) is used as a measure for the goodness of fit. For the identification of the best 1-D velocity model, we considered a selected data set of $P$ and $S$ arrival times (Fig. 2) and 12 different starting velocity models (Fig. 6 ). $S$-wave readings were not inverted, and were only included to better constrain the earthquake locations. A constant $V_{P} / V_{S}$ ratio of 1.85 was imposed, as retrieved by the modified Wadati diagram discussed in Sect. 3.2.

The best 1-D velocity model was estimated by a trial-anderror process. First, we performed several inversions considering the collected velocity models by using identical input and control parameters and systematically verifying that the formal overdetermination factor (total number of observations/number of effective unknowns) of the inverse problem 


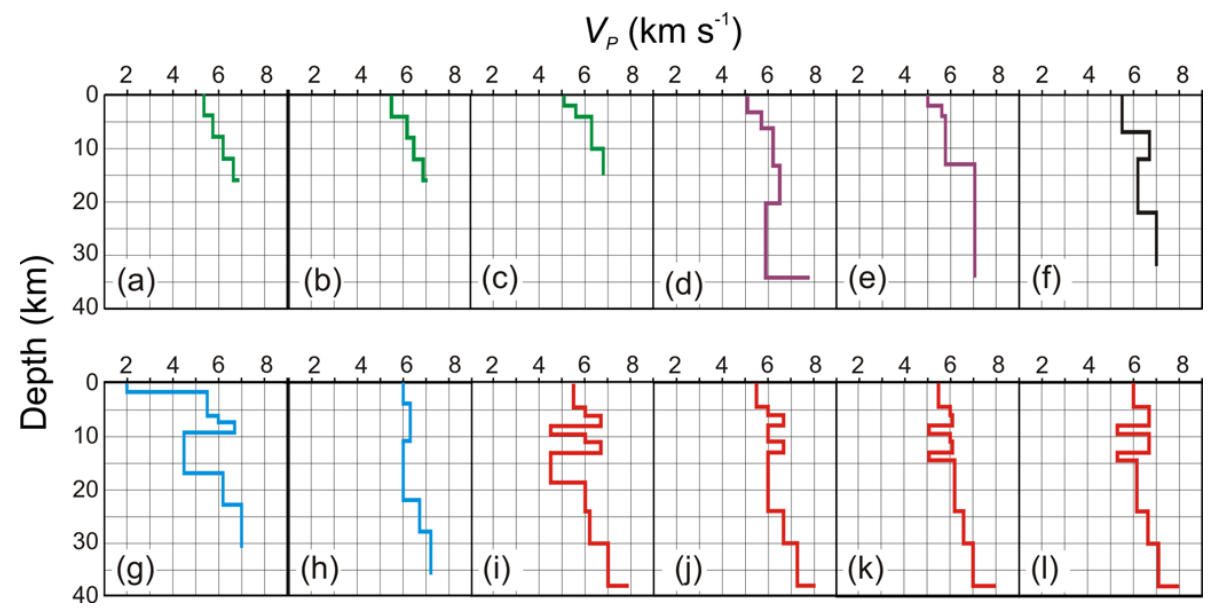

Fig. 6. Compilation of $P$-wave velocity $\left(V_{P}\right)$ models from the literature for the Sulmona area. Models derive (a-e) from seismological data, (f-h) from geophysical investigations and (i-l) from geological interpretation. Key references are as follows: (a) Bagh et al. (2007), (b) Chiarabba et al. (2009), (c) Chiarabba et al. (2010), (d) Chiarabba et al. (2005), (e) Chiarabba et al. (2005) modified, (f) Scarascia et al. (1994), (g) Patacca et al. (2008), (h) Di Luzio et al. (2009), (i-l) geostructural layering from Lavecchia and de Nardis (2009) and $V_{P}$ from many sources (Patacca et al., 2008; Di Luzio et al., 2009; Barchi et al., 2003; Trippetta et al., 2013).

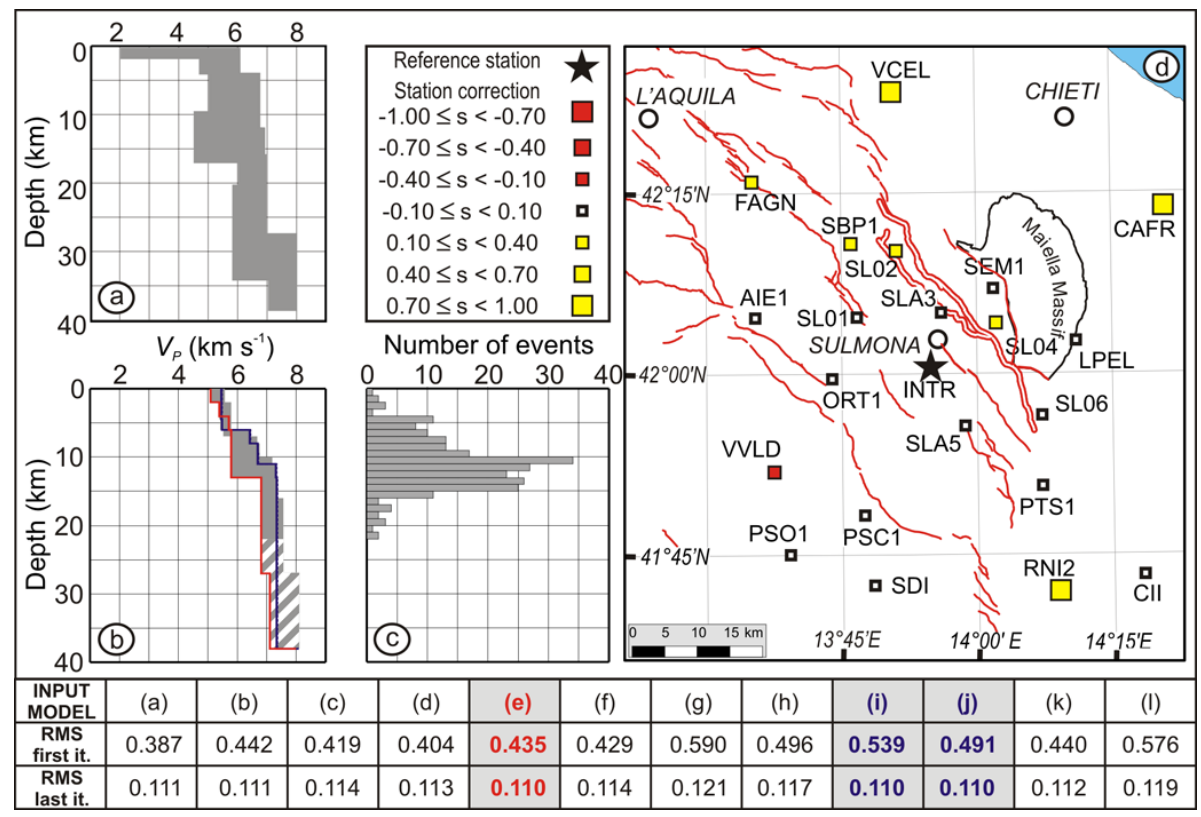

Fig. 7. 1-D velocity model in the Sulmona area. (a) Envelope (e.g. range of variability) of the starting $P$-wave velocity models individually plotted in Fig. 6. (b) Envelope (e.g. range of variability) of the best 1-D velocity models computed with the Velest code having a misfit less than or equal to $0.1 \mathrm{~s}$. The striped area represents the unconstraint depth interval of the velocity models. (c) Depth distribution of the selected events (Fig. 2) used to compute the velocity model. (d) Location map of the seismic network with station corrections related to the best model; positive values correspond to velocity slower with respect to the model. In the table the start and final RMS travel-time residual for each of the 12 used models (a-l in Fig. 6) are synthesized.

was at least greater than 1.5 . Analysing the preliminary results, we noted that the output models were quite similar in spite of the wide range of variability of the starting ones (Fig. 7a), implying a stable solution. Nevertheless, we carried out further tests varying the control parameters. Afterwards, we created new velocity structures including phantom layers in each initial model. The Velest code, however, does not automatically adjust layer thicknesses and the appropriate layering must be found by performing trial inversions. Among all the tested models with phantom layers, the model (e), shown in Fig. 6, resulted as the most representative in terms of RMS and used as additional input model. Moreover, for 
Table 2. The best 1-D velocity model estimated for the Sulmona area and its inferred composition layering.

\begin{tabular}{llll}
\hline & Lithostratigraphy & $\begin{array}{l}\text { Depth } \\
\text { interval }(\mathrm{km})\end{array}$ & $\begin{array}{l}\text { Velocity } \\
(\mathrm{km} \mathrm{s})\end{array}$ \\
\hline UPPER CRUST & Miocene turbidites and & $0-2$ & 5.1 \\
& Jurassic-Palaeocene carbonates & $2-4$ & 5.4 \\
& Triassic evaporites and late Permian-Triassic \\
& quartzites and phyllites & $4-6$ & 5.7 \\
MIDDLE CRUST & Crystalline Palaeozoic basement & 5.8 \\
LOWER CRUST & Mafic granulite & $13-27$ & 6.8 \\
MANTLE & Peridotite & $27-38$ & 7.1 \\
\hline
\end{tabular}

each model we performed 10 runs using final hypocentre locations as initial parameters for the next one. Finally, we analysed the RMS (root mean square) "misfit" trend versus the number of iterations and chose the best model (the one corresponding to the minimum misfit of travel-time residuals) for each guess velocity structure.

The obtained results are summarized in the panels and in the table of Fig. 7. Specifically, Fig. 7b shows the range of variability (grey envelope) of the calculated 1-D velocity models with best misfit less than or equal to $0.1 \mathrm{~s}$ (the value which is compatible with the uncertainty of the $P$ - and $S$-wave pickings). The table in Fig. 7 reports the start and final RMS travel-time residual for each of the 12 used models. The final velocity model (red line in Fig. 7b) was chosen considering both the inversion results and the a priori information according to Kissling et al. (1994). Specifically, we selected the best model on the basis of (1) goodness of the fit $(0.110 \mathrm{~s}),(2)$ realism of station corrections from a geological point of view, (3) consistency of the model with respect to local geological and geophysical information (see references in Fig. 6) and (4) taking into account worldwide compilations of the thickness and velocity structure of the crust in analogous tectonic provinces (Christensen and Mooney, 1995). These steps were necessary because, below $10 \mathrm{~km}$, models with a similar RMS misfit (a, b, i, j) assumed velocity values greater than $7 \mathrm{~km} \mathrm{~s}^{-1}$, disagreeing with the a priori information.

Three layers with velocity increasing from 5.1 to $5.7 \mathrm{~km} \mathrm{~s}^{-1}$ are distinguished from the surface to a depth of $6 \mathrm{~km}$, a fourth layer with velocity of $5.8 \mathrm{~km} \mathrm{~s}^{-1}$ is identified at depths between 6 and $13 \mathrm{~km}$, and a fifth layer with an average velocity of $6.8 \mathrm{~km} \mathrm{~s}^{-1}$ characterizes the interval between 13 and $27 \mathrm{~km}$ (Table 2); at higher depths, the velocity increases to an average value of $7.1 \mathrm{~km} \mathrm{~s}^{-1}$.

Based on speculative correlations between the obtained velocity model and a suitable geological compositional layering for the study area, we advance the hypothesis that the uppermost three layers (average $5.6 \mathrm{~km} \mathrm{~s}^{-1}$ ) may correspond to the upper sedimentary crust consisting of a JurassicPalaeocene carbonate sequence (limestone and dolomites) overlain by open-ramp carbonates and locally by Miocene turbidites.

The thick layer identified at depths between 6 and $13 \mathrm{~km}$ (average $5.8 \mathrm{~km} \mathrm{~s}^{-1}$ ) may represent the oversimplification of a complex thrust zone where late Triassic evaporites (Anidriti di Burano formation) are tectonically interbedded with late Permian-Triassic quarzites and phyllites (Verrucano formation). We observe that the velocity inversions which would characterize such depth interval, mainly due to the presence of the very slow Verrucano formation $\left(4.5 \mathrm{~km} \mathrm{~s}^{-1}\right.$ in Patacca et al., 2008; Trippetta et al., 2013), do not result in the final velocity model, although they were introduced in several of the starting models in Fig. 6.

The sharp increase in the velocity gradient observed at $13 \mathrm{~km}$ might represent an increase in metamorphic grade as well as a decrease in silica content, and can be interpreted as the top of the crystalline Palaeozoic basement of the middle crust. Another rather sharp increase in velocity is observed at a depth of $27 \mathrm{~km}$. In agreement with the CROP 11 results, we might interpret it as the top of the lower crust, but evidently such a value is not well resolved due to the lack of seismic activity below $\sim 24 \mathrm{~km}$ (see depth histogram in Fig. 7c).

It is important to specify that the above optimized 1-D model is suitable for most of the intra-mountain zone of the Abruzzo region, but station corrections need to be included when used on more extended areas. In fact, in Fig. 7d, it is evident that the station corrections are very low (less than $0.1 \mathrm{~s}$ ) over most of the study area, but they are slightly higher northnortheastward of Sulmona and eastward of the Maiella ridge, where the positive corrections reach $1 \mathrm{~s}$, consistent with the presence of thick terrigenous deposits of the Plio-Pleistocene Adriatic foredeep. 


\section{Final earthquake locations}

After the minimization of reading errors and the optimization of the velocity model for the study area, we went to the final earthquake locations by using the code Hypoellipse (Lahr, 1980, 1984, 1999). It provides estimates of absolute position and origin time of all events. We recall that this program is the evolution of Hypo71 (used for preliminary locations in Fig. 2): it uses a weighted regression technique and introduces a new concept of error ellipsoid, representing Gaussian error distribution not necessarily aligned with latitude, longitude and depth axes, as Hypo71 does.

Very important parameters in Hypoellipse are the so-called WEIGHT OPTIONS that rule the influence of the uncertainty associated with each reading on the location process. In order to define the best values to assign to the four parameters involved in Hypoellipse weighting scheme (RESET TEST 29 and WEIGHT OPTIONS parameters), we adopt a procedure based on genetic algorithms (Bondar, 1994). Exploration of parameter space is driven so as to minimize the target function defined as a linear combination of the averages and standard deviations of $P$ and $S$ residuals returned by Hypoellipse over the whole earthquake data set. The parameterization obtained is shown in Table 3.

Furthermore, time delays were associated with seismic stations in order to consider both their elevation and possible local anomaly of velocity under them. These corrections were automatically calculated, the former assuming a $P$-wave velocity of $4 \mathrm{~km} \mathrm{~s}^{-1}$ in the sector of crust above sea level, the latter setting the RELOCATE option and running through a number of iterations.

Finally, we located 535 earthquakes that occurred from 27 May to 31 December 2009, 352 of which are of quality A, 32 of quality B, 16 of quality $\mathrm{C}$ and 135 of quality D. This means that their horizontal and vertical $68 \%$ confidence interval $(\gamma)$ is $\gamma \leq 1.34 \mathrm{~km}$ for quality A, $1.34 \mathrm{~km}<$ $\gamma \leq 2.67 \mathrm{~km}$ for quality $\mathrm{B}, 2.67 \mathrm{~km}<\gamma \leq 5.35 \mathrm{~km}$ for quality C, and $\gamma>5.35$ for quality D (Lahr, 1999). Figure 8 shows the histograms which describe the locations of quality A events. More than $90 \%$ of these hypocentral solutions feature $P$ and $S$ residuals less than \pm 0.4 s (Fig. 8a and b), horizontal/vertical errors less than $1 \mathrm{~km}$ (Fig. $8 \mathrm{c}$ and d) and RMS less than or equal to $0.3 \mathrm{~s}$ (Fig. 8e). Only $60 \%$ of the events have azimuthal gap (GAP) less than or equal to $180^{\circ}$ (Fig. 8f); that is, their location is reliable. This result is satisfying if we consider that relatively few and small events were recorded within the STN, and among those outside, only the strongest were located by using data from other networks (RSA and RSNC), with the advantage of reducing GAP. Moreover, thanks to the enrichment of our data set, more than $30 \%$ of locations are estimated using more than 16 phases (Fig. 8g). In $45 \%$ of the cases the minimum distance between the hypocentre and the closest station is less than or equal to $5 \mathrm{~km}$, and in about $30 \%$ it is less than or equal to $10 \mathrm{~km}$ (Fig. 8h), i.e. to the inter-STN station distance.
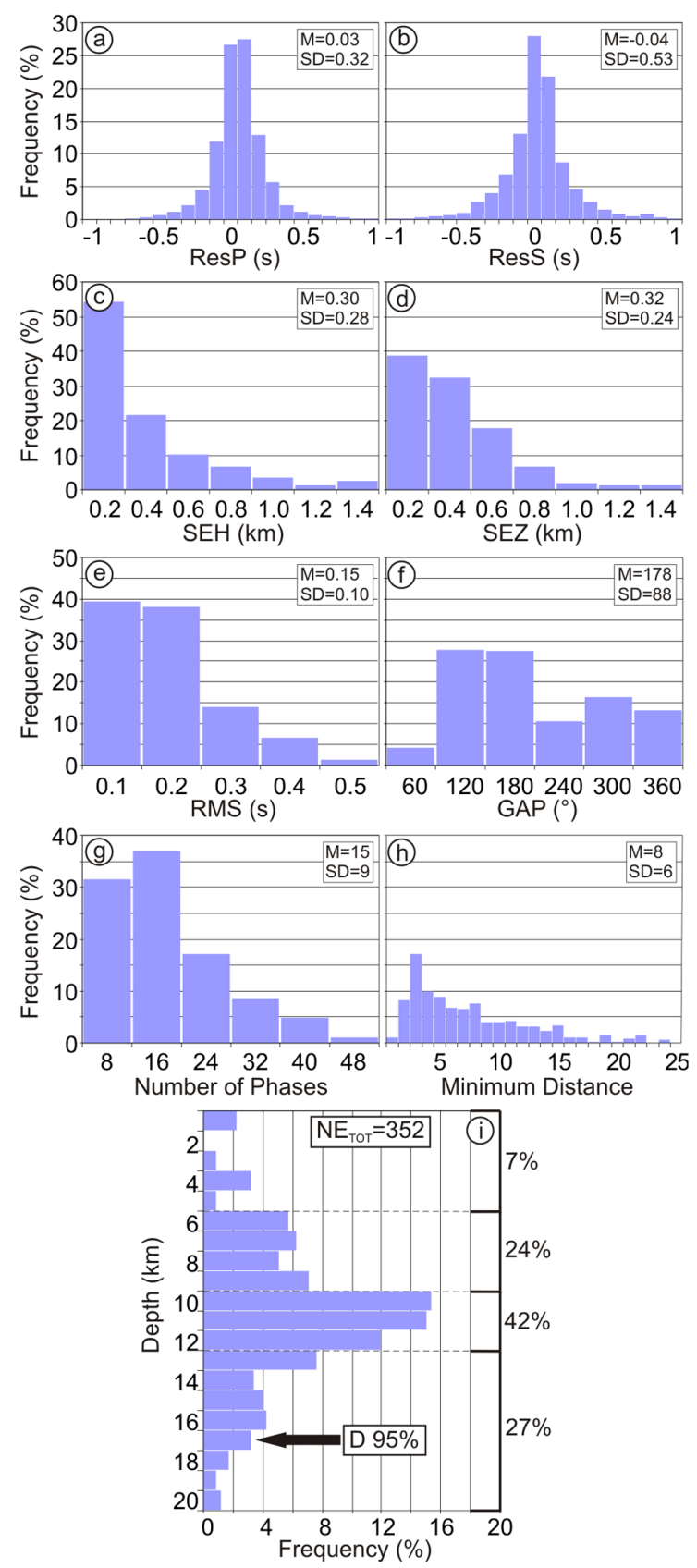

Fig. 8. Features of quality A earthquake locations. (a, b) Histograms of residuals of $P$ and $S$ phases (ResP, ResS). (c, d) Horizontal and vertical formal errors (SEH, SEZ). (e, f) Root mean square of traveltime residuals (RMS) and GAP distribution. $(\mathbf{g}, \mathbf{h})$ Number of used phases and minimum hypocentre to station distance. From (a) to (h), in the upper-right corners, the mean (M) and standard deviation (SD) of distributions are reported. (i) Depth distribution of the hypocentres. The black arrow identifies the seismogenic layer corresponding to $95 \%$ of the hypocentral distribution. On the right side the percentages of the events occurred in the depth intervals $0-5 \mathrm{~km}$, 5-9 km, 9-12 km, 12-17 km and deeper are reported. Also, the total number $\left(\mathrm{NE}_{\mathrm{TOT}}\right)$ of quality A events is indicated. 
Table 3. Weighting scheme adopted for the locations performed by using Hypoellipse. The parameter labelled with ${ }^{a}$ represents RESET TEST 29. Parameters labelled with ${ }^{b}$ represent WEIGHT OPTIONS. Refer to the Hypoellipse user's guide (Lahr, 1999) for details.

\begin{tabular}{llll}
\hline $\begin{array}{l}\text { Weight } \\
\text { code }\end{array}$ & $\begin{array}{l}\text { Standard } \\
\text { error }\end{array}$ & $\begin{array}{l}\text { Standard error relative to } \\
\text { readings with weight code zero }\end{array}$ & $\begin{array}{l}\text { Computed } \\
\text { weight }\end{array}$ \\
\hline 0 & $0.0350 \mathrm{~s}^{\mathrm{a}}$ & 1 & 1 \\
1 & $0.0455 \mathrm{~s}$ & $1.3^{\mathrm{b}}$ & $1 / 1.69$ \\
2 & $0.0700 \mathrm{~s}$ & $2.0^{\mathrm{b}}$ & $1 / 4$ \\
3 & $0.4375 \mathrm{~s}$ & $12.50^{\mathrm{b}}$ & $1 / 156.25$ \\
4 & infinite & infinite & 0 \\
\hline
\end{tabular}

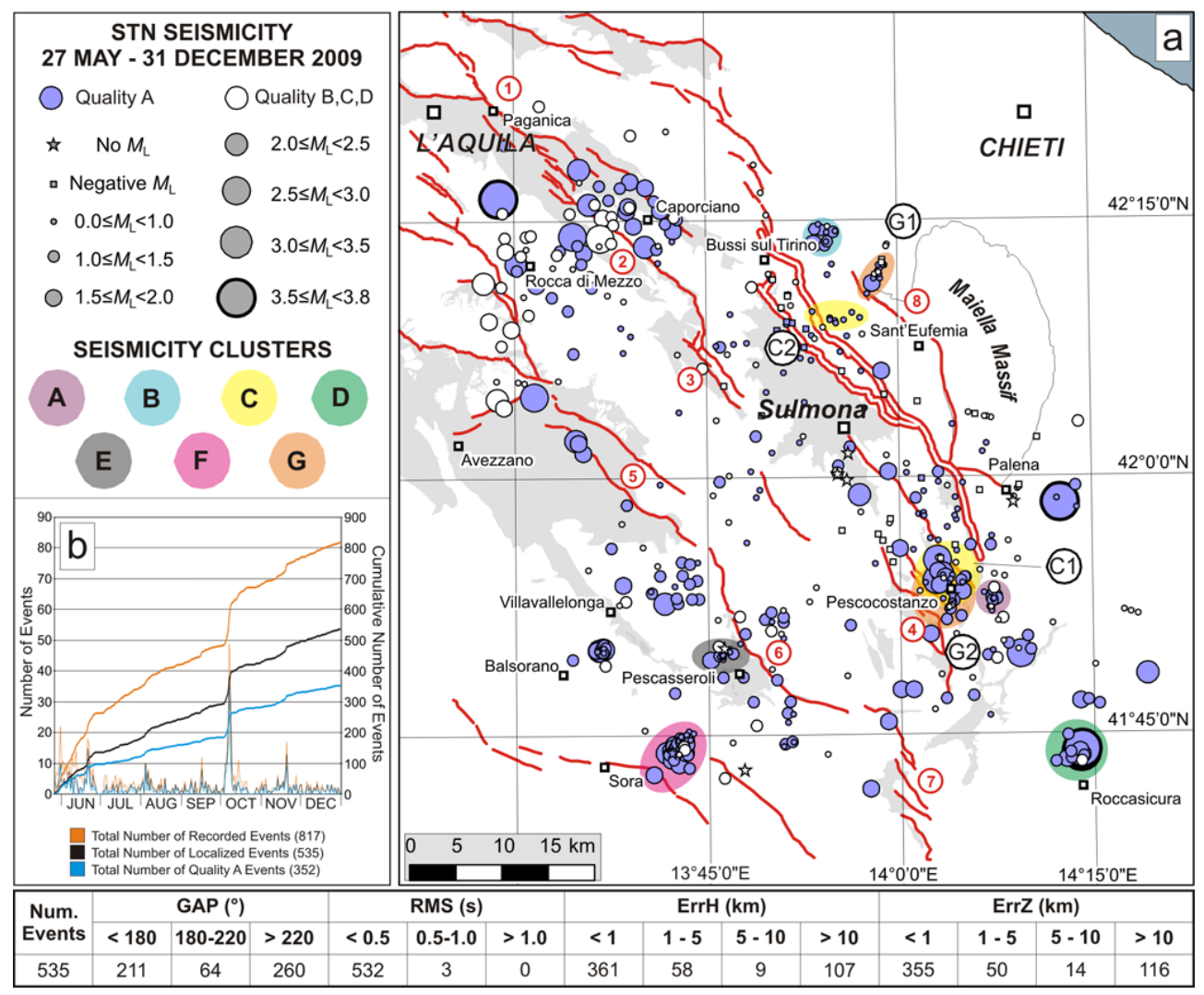

Fig. 9. Seismicity recorded by STN in the Sulmona area (Abruzzo region) from 27 May to 31 December 2009. (a) Epicentral distribution of the 535 events localized by using Hypoellipse (Lahr, 1980, 1984, 1999) and the best 1-D velocity model estimated for this area. Symbol colours refer to the quality of earthquake locations; symbol shape and dimension refer to their local magnitude. Coloured areas (A-G) point out the seismicity clusters corresponding to seismic swarms as described in the text. For location map of the represented area and legend, see Fig. 1. (b) Number and cumulative number of earthquakes versus time; location quality is given with respect to relocated events, described in Sect. 5. At the bottom is a summary of locations quality (GAP, RMS, horizontal error (ErrH) and vertical error (ErrZ)).

Final earthquake locations (Fig. 9a), obtained after building a good-quality data set and estimating the local velocity model, improve the preliminary ones (Fig. 2). Indeed background seismicity, initially widespread over the area, now tends to cluster close to known tectonic structures or, in any case, to focus on restricted areas.

\section{Magnitude, completeness and local $G-R$ relationship}

Magnitudes are computed for the final hypocentral locations previously described. We estimated them in terms of both signal amplitude $\left(M_{\mathrm{L}}\right)$ and duration $\left(M_{\mathrm{D}}\right)$.

Local magnitude $\left(M_{\mathrm{L}}\right)$ is obtained by applying Antelope's dbampmag (BRTT, 2004) and using Hutton and Boore's attenuation law (1987). In order to preserve compatibility with older magnitude estimates, $M_{\mathrm{L}}$ is calculated as the mean 
of the magnitude estimated for each station. The magnitude is evaluated from the mean of the waveform amplitude of the two horizontal components (Bormann, 2002). Single-station compensation coefficients have also been estimated and applied. They exhibit randomly distributed values smaller than \pm 0.2 , except for stations SLA3 and SLA5 (respectively +0.42 and +0.30 ), which were repositioned after logistical problems at the original sites.

Local magnitudes, which were estimated in this study, range from -1.5 to 3.7 (Fig. 10a). Of all the events, $93 \%$ have $M_{\mathrm{L}}$ between -0.1 and 2 , while the remaining $7 \%$ is distributed as follows: $2 \%$ have $M_{\mathrm{L}}<-0.1,4 \%$ have $M_{\mathrm{L}}$ between 2 and 3, and only $1 \%$ have $M_{\mathrm{L}}>3$. Furthermore, 8 of 535 earthquakes lack amplitude data due to noise problems.

By comparing our $M_{\mathrm{L}}$ estimates to those derived from ISIDE for about 200 events common to both networks (Fig. 10b), it becomes apparent that the $M_{\mathrm{L}}$ of this study is higher than that estimated by ISIDE by a value of about 0.15 .

As a shortcut to local magnitude estimation, we calculate the duration magnitude $\left(M_{\mathrm{D}}\right)$ as well. We used the following simplified formula according to Havskov and Ottemöller (2010):

$M_{\mathrm{D}}=a_{1}+a_{2} \log (\tau)$,

where $\tau$ is the signal duration in seconds; the distance term is not considered as it turned out to be negligible. Due to the presence of noise, the signal duration has not been read, and therefore $M_{\mathrm{D}}$ has not been estimated for 207 of 535 events. For the remaining 328 earthquakes $M_{\mathrm{D}}$ values range from -0.9 to 3.7 .

Mean station coefficients have been estimated by calibrating $M_{\mathrm{D}}$ against $M_{\mathrm{L}}$ (Fig. 10c) by applying ordinary leastsquares and orthogonal regressions. Duration magnitudes are then obtained by entering the coefficients of the orthogonal regression into the pertinent RESET TEST values of Hypoellipse (i.e. (31) equal to -3.2843 ; (32) equal to 3.3129 ; (33), (40) and (43) set to 0). It can be seen from Fig. 10c that the orthogonal regression represents the highest $M_{\mathrm{L}}$ fairly well, even if the data are quite dispersed.

Finally, a statistical analysis of the magnitude versus event frequency relationship and an estimation of the completeness magnitude inferred on the Gutenberg-Richter (1956) model is carried out by using Zmap software (Wiemer, 2001). The result is shown in Fig. 10d. The completeness magnitude $\left(M_{\mathrm{c}}\right)$ of our relocated data set (27 May to 31 December 2009) is 1.1. Note that the coefficients of the Gutenberg-Richter relationship, i.e. the annual $a$ value (3.49) and $b$ value (0.85), are not representative of the Sulmona Basin only, as part of the L'Aquila seismic sequence and a bulk of earthquakes in the SW Sora region (see Fig. 9a) fall inside the relocated events. If we select the events spatially in a buffer zone of $20 \mathrm{~km}$ around the STN stations, thus selecting earthquakes where the detection capabilities of the temporary network are
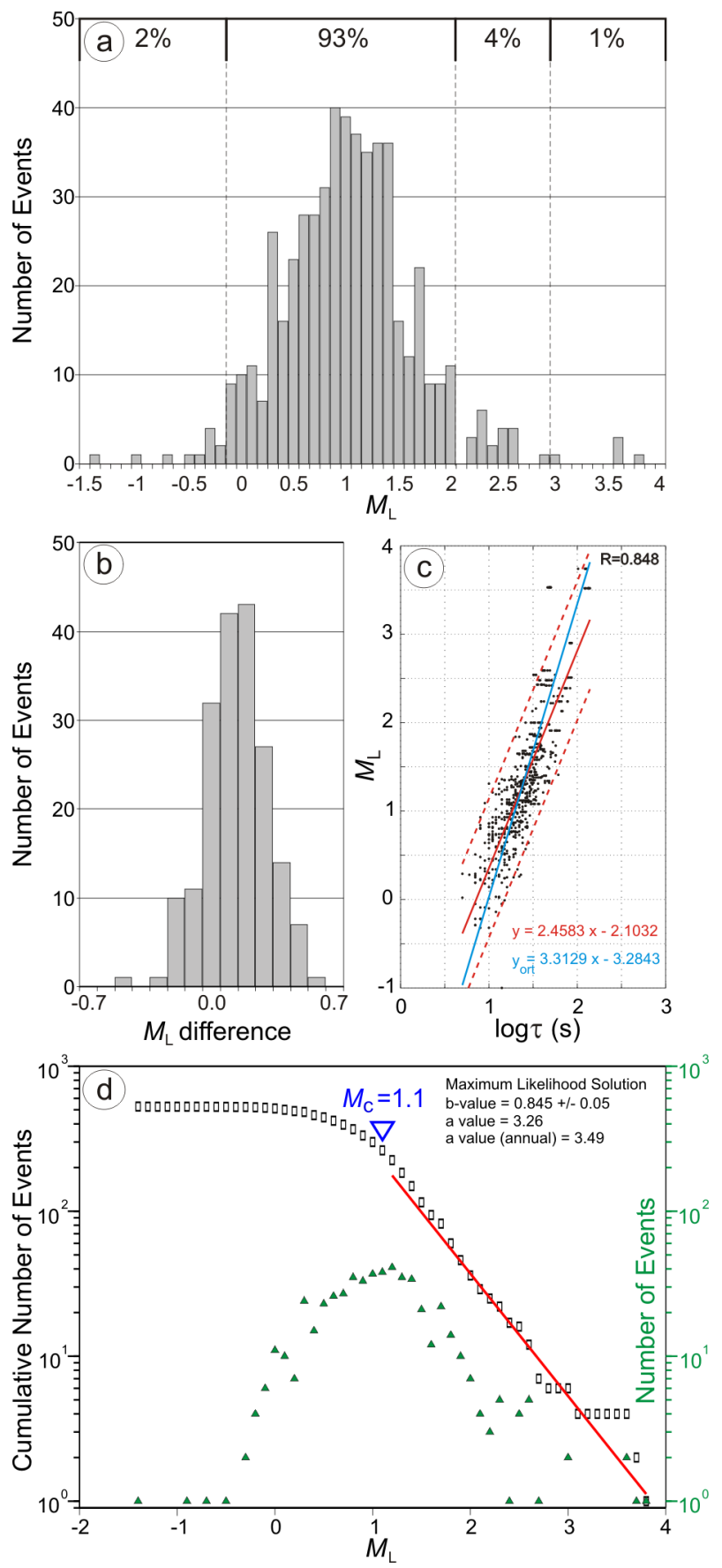

Fig. 10. (a) Histogram of $M_{\mathrm{L}}$ estimates of earthquakes localized in this study. At the top of the histogram, the percentages of the events within the corresponding range of magnitude are reported. (b) Histogram of the residuals between local magnitude estimated in this study and that reported on ISIDE database for coincident events. (c) Calibration of $M_{\mathrm{D}}$ magnitude through linear regression of $M_{\mathrm{L}}$ against event duration $(\tau)$. In red and blue, the ordinary leastsquares and orthogonal regressions, respectively. Dashed lines represent the standard deviation of ordinary least-squares regression. (d) Gutenberg-Richter slope evaluated with 527 events for which $M_{\mathrm{L}}$ has been estimated. In blue, the magnitude of completeness $M_{\mathrm{c}}$. 
at their best, we obtain $a$ equal to $3.11, b$ to 0.71 and $M_{\mathrm{c}}$ to 0.72 .

\section{Discussion and conclusions}

The present paper aims at improving the knowledge of the background seismic activity in the Sulmona Basin, an extensional active area of the central Apennines known for strong seismic hazard (Pace et al., 2006) but substantially aseismic since instrumental times (Bagh et al., 2007; Boncio et al., 2009). Thanks to the deployment of a temporary seismic network and the analysis of the first seven months of properly processed recorded data, we have obtained a detailed picture of the microseismicity that has not revealed until now by either existing permanent networks (ISIDE database; De Luca, 2011) or other similar experiments performed in the past (Bagh et al., 2007). The meta data gathered during this period were somehow peculiar and time demanding for what concerns signal treatment due to the ongoing seismic activity in the L'Aquila area. The processing combines an automatic detection procedure with operator-assisted selection of windows as well as fully manual readings of waveforms on local events (chosen on $S-P$ time delays). This approach has proved to be very effective, even though quite time consuming, in identifying even very small earthquakes, such as local events with $M_{\mathrm{L}}<-1$ recorded by only one or two stations. The integration of the STN recordings with the data gathered by regional and national permanent networks (RSA and RSNC) enriched and strengthened the location quality of the strongest earthquakes. As phases are homogeneously read and accuracy is clearly stated, a 1-D velocity model of the Sulmona area (well constrained within the first $20 \mathrm{~km}$, which is the maximum depth reached by the quality A earthquake locations) and a reliable $V_{P} / V_{S}$ ratio of 1.85 were obtained, which guarantees accurate earthquake locations and may be useful for forthcoming studies in the area.

In this paper, an online catalogue of the analysed earthquakes is compiled and released as a supplement together with the phase pickings. The catalogue contains the following: the origin times and the hypocentral coordinates of located earthquakes; all the parameters useful to establish the quality of their locations (RMS, GAP, number of phases used, minimum distance, dimension and orientation of error ellipsoids); and the magnitude estimate, with both local and duration if possible. The catalogue includes 535 events, which is about $60 \%$ more than reported in the national ISIDE database. An additional set of 282 not located earthquakes is given by phase readings only for possible further analyses. The quality location of nearly $66 \%$ of the located events is A, even though their magnitude is very small. Indeed, $99 \%$ of located seismicity is represented by ultramicro- $(M<1)$ and micro-earthquakes $\left(1 \leq M_{\mathrm{L}}<3\right)$, while only $1 \%$ is represented by small earthquakes $M_{\mathrm{L}} \geq 3$ (Hagiwara, 1964) (Fig. 10a). The completeness magnitude
$M_{\mathrm{c}}$, based on local magnitude estimates, is well constrained and reaches the value of 1.1 for the whole data set of located events. It decreases to 0.7 if only the area strictly pertaining to the STN stations is considered. This low value of $M_{\mathrm{c}}$ confirms that the adopted semi-automatic procedure based on automatic detection of events and manual picking is very effective for investigating the microseismicity.

A well-constrained $G-R$ slope was estimated from the microseismic data (Fig. 10d). We observe that the productivity rates shown by the $a$ value are nearly constant if normalized to the area outlined by the temporary stations' coverage, whereas the $b$ value decreases from 0.85 to 0.71 . Nevertheless, the shortness of the time interval investigated and the limitations in the data sample do not allow for interpreting these low $b$ values as a stress indicator (see, for example, Gulia and Wiemer, 2010). In the Sulmona area, stationary background conditions might have been influenced by static/dynamic stress changes induced by the main L'Aquila earthquakes. Evidence of stress loading in the Sulmona basinal area induced not only by the L'Aquila 2009 earthquake in the north but also by the 1984 Val di Sangro earthquake in the south was pointed out by De Natale et al. (2011) based on the results from coseismic Coulomb stress change studies.

A seismotectonic analysis of the geometric and kinematic relationship between the Sulmona microearthquake activity and the active faults in the area are beyond the scope of this paper. Nevertheless, some preliminary observations on the space-time distribution of identified clusters of seismic activity and on the overall seismogenic thickness can be advanced. We observe that the background seismicity is not uniformly distributed in the study area but rather clustered in specific zones, mainly close to known active faults (Fig. 9a). Prevailing activity is observed in the northwestern corner of the study area, which coincides with the southern end of the Paganica seismogenic source responsible for the 2009 L'Aquila earthquake $\left(M_{\mathrm{w}}=6.3\right.$, Lavecchia et al., 2012); conversely, the area of the Sulmona Plain remained almost completely aseismic during the whole of the observation time.

The temporal evolution of the recorded seismic activity, schematized as a cumulative number of events versus time (Fig. 9b), shows a sharp decrease in seismic rate at the end of June, e.g. after nearly one month of registration and nearly two months after the 6 April 2009 earthquake $\left(M_{\mathrm{w}}=6.3\right)$. The remaining portion of the cumulative slopes shows other jumps, corresponding to local and short-lasting increases in the seismic activity. Three swarms were recorded from 2 to 22 June. They occurred within the hanging wall of the Porrara Fault (cluster A, with $M_{\mathrm{L}}$ up to 1.7 , and $\mathrm{C}$, with $M_{\mathrm{L}}$ up to 2.5 in Fig. 9a), and within the footwall of the Morrone Fault (cluster B, with $M_{\mathrm{L}}$ up to 1.2 , and C2 with $M_{\mathrm{L}}$ up to 0.9 in Fig. 9a). Specifically, the swarms are placed at southern and northern tips of the Morrone-Porrara extensional alignment. 
On 4 August the area near Roccasicura (Molise region), located along the SSE-ward direction of the Morrone-Porrara extensional alignment, was affected by a small swarm of 10 earthquakes (cluster D in Fig. 9a) at depths between 13 and $17 \mathrm{~km}$, with two larger events of $M_{\mathrm{L}}=3.5$ and 3.6 (Fig. $9 \mathrm{a}$ ). Two other swarms occurred at the beginning of October 2009. The first one (12 events between 4 and 5 October, with $M_{\mathrm{L}}$ up to 1.7 ; cluster E in Fig. 9a) was located at the hanging wall of the Marsicano Fault at depths of 6-12 km; the second one ( 80 events between 6 and 8 October, with $M_{\mathrm{L}}$ up to 3.6 as in ISIDE; cluster F in Fig. 9a) nucleated near Sora (Lazio region) at a depth of 6 to $14 \mathrm{~km}$. Finally, on 19 and 20 November, another increase of seismicity, with spatial distribution similar to that of the late June activity, was recorded at the footwall of the Morrone Fault (cluster G1 with $M_{\mathrm{L}}$ up to 1.6 in Fig. 9a) and at the hanging wall of the Porrara Fault (cluster G2 with $M_{\mathrm{L}}$ up to 2.9 in Fig. 9a).

We also performed a preliminarily evaluation on the Sulmona seismogenic layer, defined as the depth layer that releases the largest number of earthquakes (i.e. $95 \%$ of the seismicity - D95; Williams, 1996; Fernandez-Ibañez and Soto, 2008). The frequency-depth histogram of Fig. 8i, which was only built on the basis of quality A earthquakes, shows that $7 \%$ of the events were shallower than $5 \mathrm{~km}, 24 \%$ occurred at depths between 5 and $9 \mathrm{~km}, 42 \%$ were concentrated in the $9-12 \mathrm{~km}$ depth interval, $22 \%$ were between 12 and $17 \mathrm{~km}$, and the remaining $5 \%$ between 17 and $21 \mathrm{~km}$. Therefore, the base of the seismogenic layer, which releases $95 \%$ of the seismicity, is located at a depth of $17 \mathrm{~km}$. A thickness of $12 \mathrm{~km}$ (from 5 to $17 \mathrm{~km}$ ) may be assumed for the brittle layer, which is considered as the layer within which nearly $90 \%$ of the seismicity occurs. These values are in agreement with other independent estimates done in this sector of the Apennines based on rheological evaluations (Boncio et al., 2009).

In conclusion, we point out that the detailed analysis and the quality study performed in this paper in order to obtain a low-magnitude complete catalogue for the Sulmona area confirm and further highlight the low seismicity rate characterizing the study area, with important implications in seismic hazard evaluation.

\section{Appendix A}

\section{Phase reading uncertainties}

Uncertainty in phase readings is rarely declared in earthquake locations and catalogues, but this is an important element because location codes use this information in their weighting schemes. Formally, the estimate of measurement error has to be evaluated from a probabilistic point of view. According to this, the onset of a seismic phase should be described by a probabilistic function that reaches its maximum exactly at the arrival time of this phase, and the standard error
Table A1. Weighting scheme adopted in the preliminary locations performed by using Hypo71 (Lee and Lahr, 1975).

\begin{tabular}{ll}
\hline $\begin{array}{l}\text { Weight } \\
\text { Code }\end{array}$ & Reading \\
Error
\end{tabular}

corresponds to the standard deviation of the population. In this way information on statistical properties of the errors could be retrieved. More often, only a qualitative evaluation of the reading error is available, and the operator's choice cannot be evaluated rigorously. Reading errors are detected by a change in the amplitude and in the frequency content of the seismic signal, and they are usually represented by a time window whose width is estimated by the operator and depends on the signal-to-noise ratio and the dominant frequency of the arriving phase (Husen and Hardebeck, 2010). Phase reading errors are then classified into categories which correspond to weight codes that are directly used by location algorithms. The larger the reading uncertainty, the higher the weight code is and the less this reading influences earthquake location. The mapping of reading errors into weights may be controlled by the seismologist, even though this is not always declared. For our preliminary earthquake locations, given in Fig. 2 in the main text, the setting of weighting scheme tuned for performing locations with Hypo71 is shown in Table A1.

Some histograms of the phase reading errors are given in Fig. A1. The data set contains readings from the STN and RSA networks obtained for this study manually, whereas we cannot retrieve the reading uncertainties for all the phases provided by the RSNC network, for which only the weight code and polarities, if any, are given. More than $90 \%$ of the $P$ and $S$ original phases have a reading error less than or equal to $0.2 \mathrm{~s}$ (see Fig. A1a), while a few outliers (seven for $P$ phases, one for $S$ phases), not represented in Fig. A1a, are in the range $0.4-0.54 \mathrm{~s}$. Thus, none of our picks is given weight 4 .

The permanent INTR station (see its location in Fig. 1) is the site with the greatest number of readings (Fig. A1b) related to local events. Also, sites SL03/SLA3, SL05/SLA5 and SL06 are well represented (about or more than $300 P$ 's). Three stations (i.e. SL01, SL04 and LPEL) have less data because of some instrumental acquisition problems (for details, see de Nardis et al., 2011). Conversely, the small number of readings on the RSA stations is probably due to the triggeredmode acquisition, which cut off the detected earthquakes at a higher threshold. 


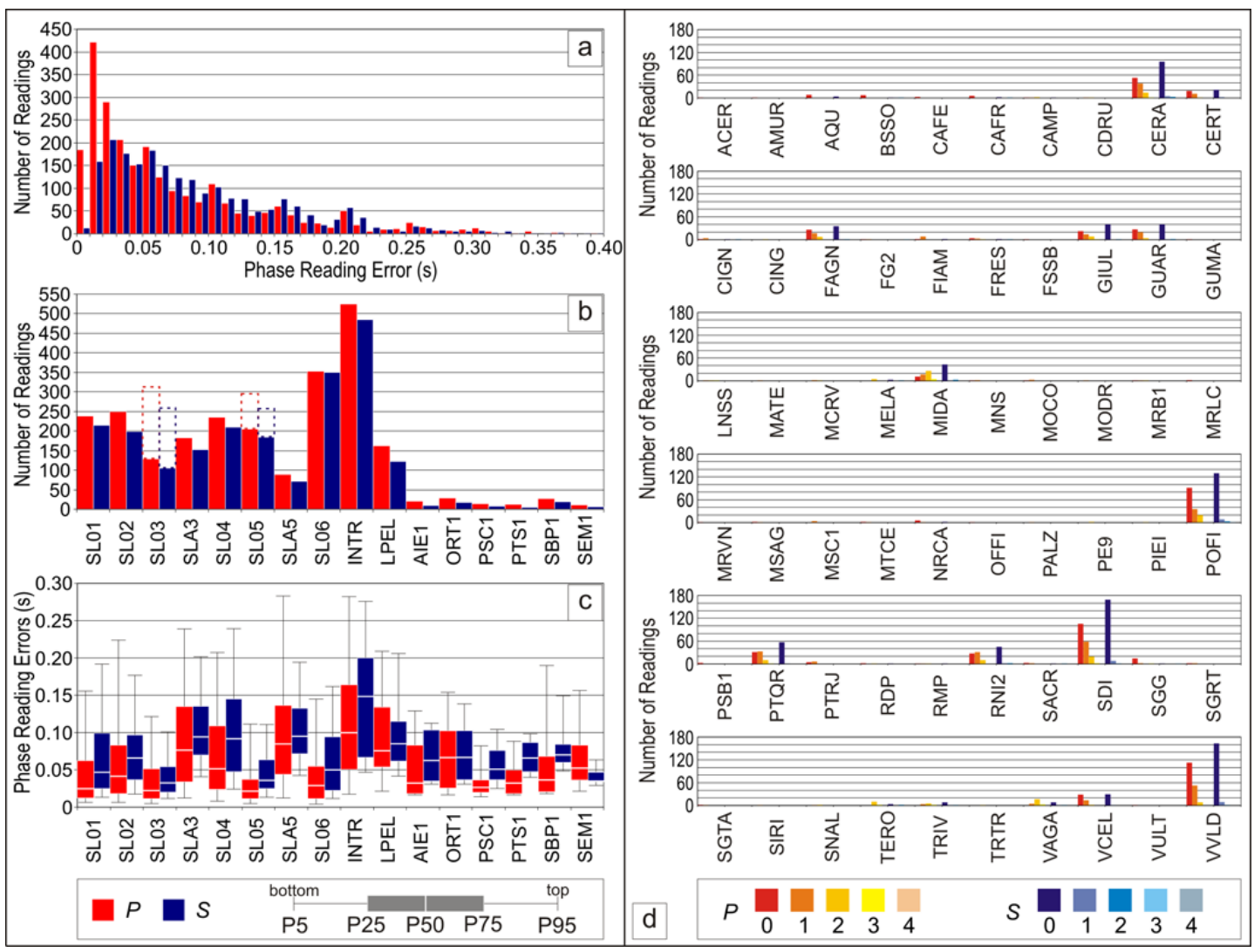

Fig. A1. Left: accuracy of pickings for all the phases read in this study. Period from 27 May to 31 December 2009. Right: weight code distribution for the RSNC stations used. (a) Number of $P$ and $S$ phases (in red and blue, respectively) versus reading errors. More than $90 \%$ of the pickings have a reading error less than or equal to $0.2 \mathrm{~s}$. (b) Number of $P$ and $S$ phases identified for each station of STN and RSA networks. The dashed columns show the sum of the phases for stations SL03/SLA3 and SL05/SLA5, which correspond to different locations of the same station at nearby sites. (c) $P$ and $S$ reading error distribution for stations of STN and RSA networks. P5 and P95 indicate the 5th and 95th percentiles of the distribution and are represented by thin, grey bars; P25 and P75 indicate the 25th and 75th percentiles and are represented by thick, coloured bars; P50 is the median, and it is represented by the thin white line inside the thick bar. (d) $P$ and $S$ weight code histograms for all the 60 RSNC stations used in this study. Red and blue colour scales represent weight codes associated with $P$ and $S$ readings, respectively.

The quality of pickings is statistically very good and similar for all the sites (Fig. A1c). For 11 of 16 stations (i.e. except for SLA3, SL04, SLA5, INTR and LPEL), both the median and 75 th percentile is within $0.1 \mathrm{~s}$; the 95 th percentile is more scattered, although it never reaches $0.3 \mathrm{~s}$. This is due to either the low sampling rate of the two permanent stations - INTR and LPEL are often sampled at $20 \mathrm{~Hz}$ due to the lack of high-sampling channels - or the high noise level of the temporary stations.

As previously said, for the other RSNC stations we have only their weight code, with no known weighting scheme. We used INGV arrival times for earthquake locations after performing some sensitivity tests using different weighting codes and schemes; the earthquake locations differ usually by about $1 \mathrm{~km}$, i.e. the same average uncertainty of our best locations. An additional check has been done for INTR and LPEL stations, for which we have both our readings and those given by RSNC operators; there is good correspondence between the two sets of $P$ and $S$ phases. Moreover, the modified Wadati plot guarantees the discharge of outlier phases and, finally, the RSNC phases represent only the $30 \%$ of the complete data set.

Therefore, we represent the histograms of weight codes for all the 60 stations, some of which sporadically enter in this data set (Fig. A1d). Only 13 of them (CERA, CERT, FAGN, GIUL, GUAR, MIDA, POFI, PTQR, RNI2, SDI, VAGA, VCEL, VVLD - the location of the stations nearest to the STN network is reported in Fig. 1) are well represented, with weight equal to 0 (best quality) assigned to $S$ phases. Only a few observations are retrieved for the remaining, more distant stations, and they refer to events already listed in ISIDE.

Thanks to this detailed description, we obtain a rough evaluation of the noise level for each station and provide a clear scheme of reading uncertainties that can be used in further analyses (e.g. tomographic inversions). 


\section{Supplementary material related to this article is available online at \\ http://www.nat-hazards-earth-syst-sci.net/13/2727/2013/ nhess-13-2727-2013-supplement.zip.}

Acknowledgements. This project is self-financed by OGS (CRS Department) and the University of Chieti (GeosisLab, headed by Giusy Lavecchia). We thank all mayors of the municipalities involved, Silvano Agostini of the regional board of the Ministry of Cultural Heritage and Environmental Conservation, and the DPC (Civil Protection Department) and the INGV (National Institute of Geophysics and Volcanology) for data exchange. Special thanks go to Gaetano De Luca (INGV) for his great work done in gathering and providing us with the data recorded by the Abruzzo Seismic Network (RSA), and also to Francesco Mele (INGV) for his precious help in retrieving the phase picking of the National Seismic Network (RSNC). We also thank the Editor Stefano Tinti and the reviewers Dario Albarello, Elena Eva and the anonymous one for the constructive remarks that improve the original manuscript.

Edited by: S. Tinti

Reviewed by: D. Albarello, E. Eva, and one anonymous referee

\section{References}

Bagh, S., Chiaraluce, L., De Gori, P., Moretti, M., Govoni, A., Chiarabba, C., Di Bartolomeo, P., and Romanelli, M.: Background seismicity in the Central Apennines of Italy: The Abruzzo region case study, Tectonophysics, 444, 80-92, 2007.

Barchi, M., Minelli, G., Magnani, B., and Mazzotti, A.: Line CROP 03: Northern Apennines, Memorie Descrittive della Carta Geologica d'Italia, LXII, 127-136, 2003.

Boncio, P., Lavecchia, G., and Pace, B.: Defining a model of 3D seismogenic sources for Seismic Hazard Assessment applications: The case of Central Apennines (Italy), J. Seismol, 8, 407425, 2004

Boncio, P., Tinari, D. P., Lavecchia, G., Visini, F., and Milana, G.: The instrumental seismicity of the Abruzzo Region in Central Italy (1981-2003): Seismotectonic Implications, Italian Journal of Geosciences (Bollettino della Società Geologica Italiana), $128,367-380,2009$

Bondar, I.: Hypocentre determination of local earthquakes using genetic algorithm, Acta Geodaetica Geophysica Hungarica, 29, 39 56, 1994.

Bormann, P.: New Manual of Seismological Observatory Practice, GeoForschungsZentrum Potsdam, 2002.

BRTT (Boulder Real Time Technology): Evolution of the Commercial ANTELOPE Software, Open file Report, available at: http: //www.brtt.com/docs/evolution.pdf (last access: 22 April 2013), 2004.

Castello, B., Selvaggi, G., Chiarabba, C., and Amato, A.: CSI - Catalogo della sismicità italiana 1981-2002, versione 1.1, INGVCNT, Roma, available at: http://csi.rm.ingv.it/ (last access: 22 April 2013), 2006.

Ceccaroni, E., Ameri, G., Gómez Capera, A. A., and Galadini F.: The 2nd century AD earthquake in Central Italy: archaeo- seismological data and seismotectonic implications, Nat. Hazards, 50, 335-359, doi:10.1007/s11069-009-9343-x, 2009.

Chatelain, J.: Étude fine de la sismicité en zone de collision continentale à l'aide d'un réseau de stations portables: la région Hindu-Kush-Pamir, Ph.D. thesis, Université Paul Sabatier, Toulouse, 1978.

Chiarabba, C., Jovane, L., and Di Stefano, R.: A new look to the Italian seismicity: seismotectonic inference, Tectonophysics, 395, 251-268, 2005.

Chiarabba, C., Amato, A., Anselmi, M., Baccheschi, P., Bianchi, I., Cattaneo, M., Cecere, G., Chiaraluce, L., Ciaccio, M. G., De Gori, P., De Luca, G., Di Bona, M., Di Stefano, R., Faenza, L., Govoni, A., Improta, L., Lucente, F. P., Marchetti, A., Margheriti, L., Mele, F., Michelini, A., Monachesi, G., Moretti, M., Pastori, M., Piana Agostinetti, N., Piccinini, D., Roselli, P., Seccia, D., and Valoroso, L.: The 2009 L'Aquila (central Italy) MW6.3 earthquake: Main shock and aftershocks, Geophys. Res. Lett., 36, L18308, doi:10.1029/2009GL039627, 2009.

Chiarabba, C., Bagh, S., Bianchi, I., De Gori, P., and Barchi, M.: Deep structural heterogeneities and the tectonic evolution of the Abruzzi region (Central Apennines, Italy) revealed by microseismicity, seismic tomography, and teleseismic receiver functions, Earth Planet. Sci. Lett., 295, 462-476, 2010.

Chiaraluce, L., Chiarabba, C., De Gori, P., Di Stefano, R., Improta, L., Piccinini, D., Schlagenhauf, A., Traversa, P., Valoroso, L., and Voisin, C.: The 2009 L'Aquila (central Italy) seismic sequence, Bollettino di Geofisica Teorica ed Applicata, 52, 367387, doi:10.4430/bgta0019, 2011.

Christensen, N. I. and Mooney, W. D.: Seismic velocity structure and composition of the continental crust: A global view, J. Geophys. Res., 100, 9761-9788, 1995.

De Luca, G.: La Rete Sismica regionale Abruzzo e sua integrazione con la RSN, in: Riassunti estesi del I Workshop Tecnico "Monitoraggio sismico del territorio nazionale: stato dell' arte e sviluppo delle reti di monitoraggio sismico", INGV, Roma, 2223, 2011.

De Luca, G., Scarpa, R., Filippi, L., Gorini, A., Marcucci, S., Marsan, P., Milana, G., and Zambonelli, E.: A detailed analysis of two seismic sequences in Abruzzo, Central Apennines, Italy, J. Seismol., 4, 1-21, 2000.

de Nardis, R., Garbin, M., Lavecchia, G., Pace, B., Peruzza, L., Priolo, E., Romanelli, M., Romano, M. A., Visini, F., and Vuan, A.: A temporary seismic monitoring of the Sulmona area (Abruzzo, Italy) for seismotectonic purposes, Bollettino di Geofisica Teorica ed Applicata, 52, 651-666, 2011.

De Natale, G., Crippa, B., Troise, C., and Pingue, F.: Abruzzo, Italy, Earthquakes of April 2009: Heterogeneous Fault-Slip Models and Stress Transfer from Accurate Inversion of ENVISATInSAR Data, Bull. Seismol. Soc. Am., 101, 2340-2354, doi:10.1785/0120100220, 2011.

Di Luzio, E., Mele, G., Tiberti, M. M., Cavinato, G. P., and Parotto, M.: Moho deepening and shallow upper crustal delamination beneath the central Apennines, Earth Planet. Sci. Lett., 280, 1-12, 2009.

Elter, F. M., Elter, P., Eva, C., Eva, E., Kraus, R. K., Padovano, M., and Solarino, S.: An alternative model for the recent evolution of the Northern-Central Apennines (Italy), J. Geodynam., 54, 5563, 2012. 
Fernandez-Ibañez, F. and Soto, J. I.: Crustal rheology and seismicity in the Gibraltar Arc (western Mediterranean), Tectonics, 27, 1$18,2008$.

Galadini, F. and Messina, P.: Early-Middle Pleistocene eastward migration of the Abruzzi Apennine (central Italy) extensional domain, J. Geodynam, 37, 57-81, 2004.

Galli, P., Galadini, F., and Pantosti, D.: Twenty years of paleoseismology in Italy, Earth-Sci. Rev., 88, 89-117, 2008.

Garbin, M. and Priolo, E.: Seismic event recognition in the Trentino area (Italy): performance analysis of a new semi-automatic system, Seismol. Res. Lett., 84, 65-74, doi:10.1785/0220120025, 2013

Ghisetti, F. and Vezzani, L.: Normal faulting, extension and uplift in the outer thrust belt of the central Apennines (Italy): role of the Caramanico fault, Basin Res., 14, 225-236, 2002.

Gori, S., Giaccio, B., Galadini, F., Falcucci, E., Messina, P., Sposato, A., and Dramis, F.: Active normal faulting along the Mt. Morrone south-western slopes (central Apennines, Italy), Int. J. Earth Sci., 100, 157-171, 2011.

Guidoboni, E., Ferrari, G., Mariotti, D., Comastri, A., Tarabusi, G., and Valensise, G.: CFTI4Med, Catalogue of Strong Earthquakes in Italy (461 B.C.-1997) and Mediterranean Area (760 B.C.1500), available at: http://storing.ingv.it/cfti4med/ (last access: 22 April 2013), 2007.

Gulia, L. and Wiemer, S.: The influence of tectonic regimes on the earthquake size distribution: A case study for Italy, Geophys. Res. Lett., 37, L10305, doi:10.1029/2010GL043066, 2010.

Gutenberg, B. and Richter, C. F.: Earthquake magnitude, intensity, energy, and acceleration (second paper), Bull. Seismol. Soc. Am., 46, 138-154, 1956.

Hagiwara, T.: Brief description of the project proposed by the earthquake prediction research group of Japan, in: Proc. US - Japan Conf. Res. Relat. Earthquake Prediction Probl., Earthquake Research Institute, Tokyo, 10-12, 1964.

Havskov, J. and Ottemöller, L.: Routine Data Processing in Earthquake Seismology, xi + 347 pp., Springer, ISBN 978-90-4818696-9, 2010.

Husen, S. and Hardebeck, J. L.: Earthquake location accuracy, Community Online Resource for Statistical Seismicity Analysis, doi:10.5078/corssa-55815573, available at: http://www.corssa. org (last access: 22 April 2013), 2010.

Hutton, L. K. and Boore, D. M.: The $\mathrm{M}_{L}$ scale in Southern California, Bull. Seismol. Soc. Am., 77, 2074-2094, 1987.

ISIDE Working Group (INGV): Italian Seismological Instrumental and parametric database, available at: http://iside.rm.ingv.it/ iside/standard/index.jsp (last access: 22 February 2012), 2010.

ISB Working Group (INGV): Italian Seismic Bulletin, available at: http://bollettinosismico.rm.ingv.it/, last access: 22 February 2012.

Kissling, E., Ellsworth, W. L., Eberhart-Phillips, D., and Kradolfer, U.: Initial reference models in local earthquake tomography, J. Geophys. Res., 99, 19635-19646, 1994.

Lahr, J. C.: HYPOELLIPSE/MULTICS: A Computer Program for Determining Local Earthquake Hypocentral Parameters, Magnitude and First-Motion Pattern, US Geological Survey Open-File Report 80-59, 59 pp., 1980.

Lahr, J. C.: HYPOELLIPSE/VAX: A Computer Program for Determining Local Earthquake Hypocentral Parameters, Magnitude and First-Motion Pattern, US Geological Survey Open-File Report 84-519, 76 pp., 1984.

Lahr, J. C.: HYPOELLIPSE: A Computer Program for Determining Local Earthquake Hypocentral Parameters, Magnitude and FirstMotion Pattern (Y2K Compliant Version), Version 1.0., US Geological Survey Open-File Report 99-23, On-Line Edition, 1999.

Lavecchia, G. and de Nardis, R.: Seismogenic sources of major earthquakes of the Maiella area (Central Italy): constraints from macroseismic field simultaions and regional seimotectonics, UR 4.01-S1-29, Poster at the INGV-DPC meeting, Rome, November, 2009.

Lavecchia, G., Ferrarini, F., Brozzetti, F., de Nardis, R., Boncio, P., and Chiaraluce, L.: From surface geology to aftershock analysis: Constraints on the geometry of the L'Aquila 2009 seismogenic fault system, Italian J. Geosci., 131, 330-347, doi:10.3301/IJG.2012.24, 2012.

Lee, W. H. K. and Lahr, J. C.: HYP071 (Revised): A Computer Program for Determining Hypocenter, Magnitude and First-motion Pattern of Local Earthquakes, US Geological Survey Open File Report 75-311, 1975.

Lee, W. H. K. and Stewart, S. W.: Principles and Applications of Microearthquake Networks, Academic Press, New York, 293 pp., 1981.

Lomax, A.: SeisGram2K (5.3), Mouans-Sartoux, available at: http:// alomax.free.fr/seisgram/SeisGram2K.html (last access: 22 April 2013), 2008

Margheriti, L., Chiaraluce, L., Voisin, C., Cultrera, G., Govoni, A., Moretti, M., Bordoni, P., Luzi, L., Azzara, R., Valoroso, L., Di Stefano, R., Mariscal, A., Improta, L., Pacor, F., Milana, G., Mucciarelli, M., Parolai, S., Amato, A., Chiarabba, C., De Gori, P., Lucente, F. P., Di Bona, M., Pignone, M., Cecere, G., Criscuoli, F., Delladio, A., Lauciani, V., Mazza, S., Di Giulio, G., Cara, F., Augliera, P., Massa, M., D’Alema, E., Marzorati, S., Sobiesiak, M., Strollo, A., Duval, A. M., Dominique, P., Delouis, B., Paul, A., Husen, S., and Selvaggi, G.: Rapid response seismic networks in Europe: lessons learnt from the L'Aquila earthquake emergency, Ann. Geophys., 54, 392-399, doi:10.4401/ag-4953, 2011.

Pace, B., Peruzza, L., Lavecchia, G., and Boncio, P.: Layered Seismogenic Source Model and Probabilistic Seismic-Hazard Analyses in Central Italy, Bull. Seismol. Soc. Am., 96, 107-132, 2006.

Patacca, E., Scandone, P., Di Luzio, E., Cavinato, G. P., and Parotto, M.: Structural architecture of the central Apennines: interpretation of the CROP 11 seismic profile from the Adriatic coast to the orographic divide, Tectonics, 27, TC3006, doi:10.1029/2005TC001917, 2008.

Peruzza, L., Pace, B., and Visini, F.: Fault-Based Earthquake Rupture Forecast in Central Italy: Remarks after the L'Aquila Mw 6.3 Event, Bull. Seismol. Soc. Am., 101, 404-412, doi:10.1785/0120090276, 2011

Rovida, A., Camassi, R., Gasperini, P., and Stucchi, M. (Eds.): CPTI11, la versione 2011 del Catalogo Parametrico dei Terremoti Italiani, Milano, Bologna, available at: http://emidius.mi. ingv.it/CPTI11/ (last access: 22 April 2013), 2011.

Scarascia, S., Lozej, A., and Cassinis, R.: Crustal structures of the Ligurian, Tyrrhenian and Ionian seas and adjacent onshore areas interpreted from wide angle seismic profiles, Bollettino di Geofisica Teorica ed Applicata, 36, 5-19, 1994. 
Trippetta, F., Collettini, C., Barchi, M. R., Lupattelli, A., and Mirabella, F.: A multidisciplinary study of a natural example of $\mathrm{CO}_{2}$ geological storage in central Italy, Int. J. Greenhouse Gas Control, 12, 72-83, 2013.

Wiemer, S.: A Software Package to Analyze Seismicity: ZMAP, Seismol. Res. Lett., 72, 373-382, available at: http://www. earthquake.ethz.ch/software/zmap (last access: 22 April 2013), 2001.
Williams, C. F.: Temperature and the seismic/aseismic transition: Observations from the 1992 Landers earthquake, Geophys. Res. Lett., 23, 2029-2032, 1996.

Working Group OASIS - The OGS Archive System of Instrumental Seismology, available at: http://oasis.crs.inogs.it (last access: 22 April 2013), 2011. 